JPL D-8045

SP-100 Operational Life Model

Fiscal Year 1990 Annual Report

Richard Ewell

Henry Awaya

December 14, 1990

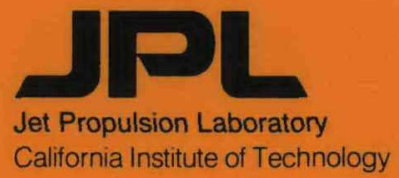




\section{DISCLAIMER}

This report was prepared as an account of work sponsored by an agency of the United States Government. Neither the United States Government nor any agency Thereof, nor any of their employees, makes any warranty, express or implied, or assumes any legal liability or responsibility for the accuracy, completeness, or usefulness of any information, apparatus, product, or process disclosed, or represents that its use would not infringe privately owned rights. Reference herein to any specific commercial product, process, or service by trade name, trademark, manufacturer, or otherwise does not necessarily constitute or imply its endorsement, recommendation, or favoring by the United States Government or any agency thereof. The views and opinions of authors expressed herein do not necessarily state or reflect those of the United States Government or any agency thereof. 


\section{DISCLAIMER}

Portions of this document may be illegible in electronic image products. Images are produced from the best available original document. 
JPL D-8045

\title{
SP-100 Operational Life Model Fiscal Year 1990 Annual Report
}

\author{
Richard Ewell \\ Henry Awaya
}

DISCLAIMER

This report was prepared as an account of work sponsored by an agency of the United States Government. Neither the United States Government nor any agency thereof, nor any of their employees, makes any warranty, express or implied, or assumes any legal liability or responsibility for the accuracy, completeness, or usefulness of any information, apparatus, product, or process disclosed, or represents that its use would not infringe privately owned rights. Reference herein to any specific commercial product, process, or service by trade name, trademark, manufacturer, or otherwise does not necessarily constitute or imply its endorsement, recommendation, or favoring by the United States Government or any agency thereof. The views and opinions of authors expressed herein do not necessarily state or reflect those of the United States Government or any agency thereof.

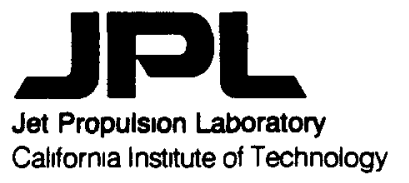


Blank Page 
CONTENTS

Section

Page

1 INTRODUCTION ......................... . . . . . . .

2 OPERATIONAL LIFE MODEL OBJECTIVES . . . . . . . . . . . . 2 . 1

3 BACKGROUND OF DEGRA ..................... . . . $3-1$

4 BACKGROUND OF THE SYSTEM CODE .................. . . 4-1

5 PERFORMANCE CODE DEVELOPMENT .................. . . 5-1

6 CODE UPDATES . . . . . . . . . . . . . . . . . . . 6-1

7 OLM CODE ARCHITECTURE . . . . . . . . . . . . . . . . . . . . 7-1

8 DEgRAdATION PARAMETERS .................... . . 8-1

9 PRELIMINARY DEGRADATION SENSITIVITIES . . . . . . . . . . . 9-1

10 PLANS . . . . . . . . . . . . . . . . . . . . . $10-1$

11 REFERENCES. . . . . . . . . . . . . . . . . . . 11-1 DISTRIBUTION . . . . . . . . . . . . . . . . . . . DL-1 


\section{Figure}

1 OLM Flow Chart . . . . . . . . . . . . . . . . . . F-1

2 Baseline Electric Power vs Time... . . . . . . . . . . . . F-2

3 Baseline Reactor Temperature vs Time . . . . . . . . . . . . F-3

4 Z-Value vs Time . . . . . . . . . . . . . . . . . . . . . F-4

5 Heat Pipes Lost vs Time . . . . . . . . . . . . . . . . . F-5

6 Baseline Radiator Temperature vs Time . . . . . . . . . . . F-6

7 Effect of Primary Pressure Drop on Electric Power vs Time . . . . F-7

8 Effect of Primary Pressure Drop on Reactor $\Delta \mathrm{T}$ vs Time . . . . . . F-8

9 Effect of Secondary Pressure Drop on Electric Power vs Time . . . F-9

10 Effect of Secondary Pressure Drop on Radiator $\Delta T$ vs Time . . . . F-10

11 Effect of Secondary Pressure Drop on Radiator Temperature vs Time... . . . . . . . . . . . . . . . . . . . . . F-11

12 Effect of Thermal Contact Resistance on Electric Power vs Time . F-12

13 Effect of Thermal Contact Resistance on PCSS Parasitic $\Delta T$ vs Time... . . . . . . . . . . . . . . . . . . . . F-13

14 Effect of Electrical Contact Resistance on Electric Power vs Time. . . . . . . . . . . . . . . . . . . . . . . . F-14

15 Effect of Electrical Contact Resistance on Contact Resistance Losses vs Time. . . . . . . . . . . . . . . . . . . . F-15

16 Effect of Electrical Contact Resistance on Reactor $\Delta T$ vs Time . . F-16

17 Effect of Radiator Emissivity on Electric Power vs Time . . . . . F-17

18 Effect of Radiator Emissivity on Radiator Temperature vs Time . . F-18

Table

\section{LIST OF TABLES}

1 SP-100 OLM Results for SDR Baseline . . . . . . . . . . . . . T T-1

2 SP-100 OLM EOL Performance ................. . T-3

3 SP-100 OLM Inputs . . . . . . . . . . . . . . . . . . . T T-5

4 OLM Output vs Time . . . . . . . . . . . . . . . . . . . . . . T-10

5 Degradation Mechanisms Categorized Into Degradation Models . . . T-11 


\section{SECTION 1}

\section{INTRODUCTION}

This report covers the initial year's effort in the development of an Operational Life Model (OLM) for the SP-100 Space Reactor Power System.

The initial step undertaken in developing the OLM was to review all available documentation from GE on their plans for the OLM and on the degradation and failure mechanisms envisioned for the SP-100. In addition, the DEGRA code developed at JPL, which modelled the degradation of the General Purpose Heat Source based Radioisotope Thermoelectric Generator (GPHS-RTG), was reviewed (Ref 1).

Based on the review of the degradation and failure mechanisms, a list of the most pertinent degradation effects along with their key degradation mechanisms was compiled. This was done as a way of separating the mechanisms from the effects and allowing all of the effects to be incorporated into the ouM. The emphasis was on parameters which will tend to change performance as a function of time and not on those that are simply failures without any prior degradation.

The JPL SP-100 System Code was used as the starting point for developing the Operational Life Model. First, the System Code was modified to make it more easily adapted into an operational life model. The inputs and outputs were separated from the main program and made into individual subroutines. The code output was simplified and shortened into a more useful format to be used within the OLM. Finally, the code was modified to run with a fixed geometry and allow a reactor coolant outlet temperature to be input and calculate the required thermal power produced by the reactor and the net generated electrical power. In addition, the code was further modified to allow the reactor coolant outlet temperature to be varied in order to obtain a desired net electrical power to the user. These modifications allow the Operational Life Model to follow a user power profile and determine how the reactor temperature adjusts through time, or to keep a constant reactor temperature and determine how the user power degrades with time.

The steady state OLM code was further modified so that it would reflect the GFS design presented at SDR. It was changed to allow any number of secondary loops to fail. Currently, the code is capable of calculating the system performance with 11 of 12 secondary loops operational. A subroutine which analyzes the performance of the auxiliary cooling loop (ACL) was incorporated into the code. Another area of modifications has been in improving the heat rejection performance calculations and incorporating an updated subroutine which calculates the damage from the impacts of meteoroids and debris. Finally, both the reactor and shield geometry and mass calculations were updated to better reflect the design at SDR. Following these updates the model was compared to the performance GE predicted at SDR. There was good correlation between the system model and GE's predicted results. The masses were within a couple of hundred kilograms and the main performance differences were within the heat rejection subsystem. The OLM utilizes the standard NASA model for meteoroid damage, which resulted in more penetrations than did the GE analysis. As a result of this, the OLM estimates that a reactor temperature of 1387 Kelvin will be needed at the end of life to deliver 100 kilowatts of electrical power to the user, with one secondary loop failed, rather than the 1375 Kelvin that GE estimated. Finally, the OLM was modified to incorporate time steps into the code. Now the code can be run from the beginning of mission to the end of mission. Initially, the code adjusts the reactor outlet temperature to maintain a fixed power output to the user of 100 
kilowatts, until the peak reactor outlet temperature of $1375 \mathrm{~K}$ is obtained. Thereafter, the reactor outlet temperature is fixed at $1375 \mathrm{~K}$ and the power output is allowed to decrease with time. In order to more easily track how various parameters change with time, the output was modified to allow both tabular and graphical output as a function of time.

In order to verify the proper operation of the code and to perform some preliminary sensitivity studies, five different performance degradation effects were incorporated into the OLM. This allows the primary and secondary pressure drop, the power conversion subsystem and Thermoelectric-Electromagnetic (TEM) pump electrical and thermal contact resistances, and the radiator emissivity to vary as a function of time. These studies did verify the proper operation of the OLM. A complete listing of the code is included in Ref. 2 . 
The goal of the OLM task is to develop a comprehensive computer code which will predict the performance of the SP-100 Space Reactor Power System as a function of time. The model will perform a steady state thermal, hydraulic, and electrical analysis at each time step taking into account any changes that have occurred in the system. Ultimately the OLM will be crucial to the validation of the SP-100 performance. Since it is not feasible to test the SP-100 system for 7 years, the current design requirement, it will be necessary to validate the design by using an OLM whose degradation and performance models have been validated by tests.

The code will be capable of varying the operational environment, duty cycle, and level of technology and degradation rates. Thus, it can assess the degradation impact of different environments, whether they are associated with earth orbit, interplanetary, or even hostile threat. The code will also be able to evaluate the impact of different duty cycles, and changes in reactor power level and temperature throughout the mission.

The code will also aid in validation and technology development. It will help to evaluate the importance of different degradation mechanisms through bounding and parametric studies. It, also, will aid in the identification and description of life tests through the postulation of degradation dependencies and the prediction of degradation rates. Accelerated life tests can then be devised which will either verify or disprove the proposed degradation models. Ultimately, almost all of the degradation models will have to be verified through testing, this is one of the reason why the code is focused on degradation effects rather than mechanisms.

The code is being developed as a joint effort of Systems Engineering and Space Subsystems. Both were supporting the task as the rate of one-half person per year. The principal focus of the Systems Engineering support, Richard Ewell, was the development of the architecture for the OLM, and running parametric and sensitivity studies and the general coordination of the OLM effort. The principal task of the the Space Subsystems support, Henry Awaya, was the development of the detailed degradation analysis models.

The computer requirements for running the OLM were reviewed. It was decided that it would be more cost effective and useful to develop the code to run on a microcomputer. In order to facilitate code development, a faster microcomputer, one with a $33-\mathrm{MHz}$ Intel 386 microprocessor, was ordered and is being utilized. In addition, it was decided that because of the heritage from the System Code, the OLM is being developed in FORTRAN 77. 
The OLM shares a common legacy with the earlier developed DEGRA in that an attempt is made in both programs to model the performance of a thermoelectric based power conversion system as a function of time (Ref. 1). DEGRA, however, was developed specifically to model the time dependent performance of a Radioisotope Thermoelectric Generator (RTG) which has the property that the power decays naturally with time, whereas, the OLM attempts to model a more complex power system which has as its heat source a controllable nuclear reactor operating at an electric power level more than one hundred times greater than the radioisotope power system. The other major difference is in the complexity of the subsystems. The thermoelectric power module modelled in the OLM is based upon a multicouple type thermoelectric structure which is conductively coupled to the heat source via a heat transport system. Additionally, this power system requires an extensive pumped loop system with heat pipes to reject heat.

The DEGRA program was developed to predict the long term performance behavior of a RTG using SiGe thermoelectric unicouples. Specifically, DEGRA has been used to model the RTGs utilized by the Voyager, Ulysses and Galileo space missions. The three primary power reducing mechanisms accounted for by DEGRA are: 1) Radioisotope fuel decay which is a function of the half life of the radioisotope used, in this case, plutonium-238. 2) Thermoelectric material property changes, based upon dopant precipitation, which accounts for the limited solubility of the dopants, and the reduction of thermal conductivity due to material alloying. 3) Material sublimation at elevated temperatures which causes changes in the dimensions of hot shoes and SiGe legs and through chemical reaction and deposition causes a decrease in electrical resistance between the unicouple and thermal insulation and the change in the thermal conductance of the multifoil nsulation.

It is important to note that the mechanisms and their effects described above are not necessarily mechanistically addressed by DEGRA. The radioisotope decay phenomena is modelled by an exponential decay equation which does not get into the specifics of nuclear decay (only the gross effect of thermal power reduction is important) and all of the material property related phenomena were grouped together in terms of gross property variation of resistivity, conductivity, and Seebeck parameters as a function of temperature and time. The program interpolates and integrates values of these properties which exist in tables and utilizes the resultant integrated values to calculate overall conductivities, resistances, thermal power, temperature distributions and ultimately the total electrical power. Additionally, there are subroutines to handle the sublimation phenomena itself in terms of the "necking" and shortening of the elemental area, as well as its impact on the electrical shunt resistance and thermal resistance of the system.

In summary, DEGRA, a program which evolved over five years of development, considered a large number of degradation mechanisms and distilled them into a smaller number of degradation effects to result in an effective model for evaluating the power variation over time for RTG type power systems. 
The OLM is a direct evolutionary descendant of the SP-100 System Code which was developed over a period of five years starting near the beginning of Phase I of the SP-100 Project to just prior to the System Design Review which took place in May of 1988. In Phase I the SP-100 Project was in the process of downselecting to the preferred power conversion option. At that time there were several contractors in competition for the System contract. The power conversion options considered were: 1) Thermoelectrics, 2) Thermionics, 3) Stirling Cycle and 4) Brayton Cycle. The original system codes were written in support of the effort to evaluate the four systems proposed by the contractors. JPL undertook the task of organizing this effort by setting up the architecture, writing, and assemblying the four power conversion based codes. This was an interlaboratory effort which included inputs from the Los Alamos National Laboratory (LANL) and NASA-Lewis Research Center (LeRC). LANL provided the nuclear subsystem subprograms or subroutines for the reactor and shield and LeRC provided Brayton and Stirling power conversion routines. JPL provided the thermoelectric and thermionic power conversion routines as well as subroutines for heat transport, heat rejection, balance of system, and power conditioning.

At the end of Phase $I$, thermoelectrics were selected as the power conversion option and the SP-100 Project entered into a ground engineering development phase. The System code development continued with periodic improvements made to the power conversion and heat rejection subsystems. There was no further developmental work on the System Code after the System Design Review in 1988 until it was necessary for development of the OLM to provide a firm baseline from which the OLM could further be developed. This activity occurred in FY 1990 and is discussed in the section on Code Updates. 


\section{SECTION 5}

\section{PERFORMANCE CODE DEVELOPMENT}

The System Code allowed for much of the geometry to be automatically varied in order to optimize the system to minimize mass and maximize power over a wide range of requirements. The main parameters that were fixed for the system code was the reactor thermal power output, the fluid outlet temperature from the reactor, and the radiator geometry. The code then varied the cold side temperature until the amount of heat rejected from the radiator matched the amount of heat that needed to be rejected from the PCSS. During this process, many geometric characteristics of the system were varied. This included varying the thermoelectric couple length and $n$ to $p-l e g$ area ratio, and the external to internal load resistance ratio. These needed to be varied to assure that the thermal input into the PCSS would yield the assumed temperature differential. In the system model, the TEM pump length was varied to obtain the required pressure rise for a fixed primary and secondary temperature drop. The heat exchanger geometry was also allowed to vary to maintain a fixed fluid flow velocity through both the hot and cold side heat exchangers of the PCSS.

The code was modified for the OLM in order to fix all of the PCSS geometry, the TEM pump geometry and all of the geometry within the ACL. In order to accomplish this, eight parameters were allowed to vary simultaneously in order for the system performance to converge. Now that the TEM pump geometry was fixed, the primary and secondary temperature differential was varied, within both the main system and the ACL, in order to utilize the available pressure rise provided by the pumps. The reactor thermal power and the cold junction temperature for the thermoelectric cell were allowed to vary in order to match the heat flow throughout the system for a fixed fluid outlet temperature from the reactor. Similarly, the amount of heat removed by the ACL and the cold junction temperature of the thermoelectric cells within the ACL were allowed to vary to match the heat flow throughout the ACL. In addition, the code was further modified to vary the reactor coolant outlet temperature to obtain a desired net electrical power to the user. These modifications allow the Operational Life Model to follow a user power profile and determine how the reactor temperature adjusts through time, or to keep a constant reactor temperature and determine how the user power degrades with time. Typically, a combination of these two are used. The reactor temperature is allowed to increase as the system degrades, in order to maintain 100 kilowatts of power available to the user. However, when the reactor temperature reaches a threshold temperature, then the reactor temperature is maintained at a constant level and the user power is allowed to decrease with further system degradation.

The OLM code also uses a modified input and output from that developed for the system code. The inputs and outputs were separated from the main program and made into individual subroutines. The code output was simplified and shortened into a more useful format to be used with the olM. Major portions of the output were separated into detailed outputs which can be requested if desired, but are not routinely printed. In addition, in order to more easily track how various parameters change with time, the output was modified to allow both tabular and graphical output as a function of time as well. 


\section{SECTION 6}

\section{CODE UPDATES}

The steady state system performance code was modified to allow any number of secondary loops to fail. Currently, the code is capable of calculating the system performance with 11 of 12 secondary loops operational.

A subroutine which analyzes the performance of the auxiliary cooling loop was incorporated into the code. This includes a detailed analysis of the TEM pump, primary piping, power conversion, secondary plumbing and heat rejection parts of the ACL.

Both the reactor and shield geometry and mass calculations were updated to better reflect the design at SDR. The primary piping was updated to best reflect the configuration presented at SDR. In addition both the heat rejection and PCC \& $D$ were updated. The power conversion subsystem was updated to better account for the variety of thermal and electrical contact resistances. The TEM pump was updated to reflect better data for the material properties of components and more realistic thermal and electric contact resistances.

The system code, as well as GE's SDR design, only included two degradation effects. The first was the decrease in thermoelectric material effectiveness with time as a result of dopant precipitation and alloying. The second is the result of damage from the impact of meteoroids and debris. Both of these degradation models were updated to better reflect available data and to be able to calculate the amount of degradation at any time during the mission.

The material properties contained within DEGRA for standard silicon germanium as a function of time and temperature were incorporated into a new subroutine. This permits the evaluation of the thermoelectric material properties at any given time and temperature for standard silicon germanium as defined by DEGRA. Then a set of equations were developed to convert the standard silicon germanium properties as a function of temperature after 1500 hours of aging to the properties assumed by GE at SDR for improved silicon germanium at 1500 hours. It was then assumed that the improved silicon germanium would degrade at the same rate as standard silicon germanium does.

The meteoroid and debris subroutines from the SP-100 System Code were updated and integrated together into a single subroutine. The improvements to the code include the added capability of evaluating altitude effects for the meteoroid flux. This involves the evaluation of body shielding and gravitational defocussing effects which modify the flux. In practice, the sum total effect of these two factors causes approximately a 108 decrease in the flux from free space to low earth orbit. The debris portion of the code has a switch which can be turned "on" for the recently added Kessler debris environmental model or the SP-100 specification environment.

In addition to the above updates, the meteoroid and debris damage models were restored to the SP-8d,42 standard NASA model. The current Technical Specification Rev. 7 dictates the use of SP-8042 for damage evaluation. The earlier system code, anticipating updates to the technical specification incorporated a Charter-Summers damage model which related a semi-infinite object damage analysis to thin object evaluation. The model utilizes a thick to thin correlation factor which is the ratio between semi-infinite objects to thin objects. Currently, there is little experimental data to validate the thick to thin correlation factor for the materials of interest (beryllium, titanium, and carbon-carbon). 
The tests we have seen are for beryllium pipes at various angles and they appear to point toward a value of 1.5 to 3.0 for the correlation factor but the evidence is shaky at best and far from conclusive. The system code used a thick to thin factor of 1.5 which understated the protection needed against a given meteoroid or debris mass. Analysis showed that a thick to thin factor of about 2.2 will give damage results similar to results obtained by using SP-8042. Usage of the factor 1.5 by the earlier system code resulted in a smaller number of heat pipes penetrated than in the NASA SP-8042 damage model case. Predictably, the OLM, which utilizes the NASA SP-8042 damage model, indicates a higher number of heat pipes penetrated over the system lifetime than did GE at SDR.

Following these updates the model was compared to the performance GE predicted at SDR. There was good correlation between the system model and GE's predicted results. The masses were within a couple of hundred kilograms and the main performance differences were within the heat rejection subsystem. The JPL code, when it utilized the same damage model as GE for meteoroids and debris, effectively produced the same performance results as GE, see Table 1. However, when the NASA model for meteoroid damage was utilized, which resulted in more penetrations than did the GE analysis, the performance was lower. As a result of this, the JPL code estimates that a reactor temperature of $1387 \mathrm{Kelvin}$ would be needed at the end of life to deliver 100 kilowatts of electrical power to the user rather than the 1375 Kelvin that GE estimated, see Table 2.

Following the update of the code, it was analyzed relative to its efficiency of operation. Initially, it took nearly 3 minutes to run the initial data point. After some modifications to the convergence methods and changes to the heat pipe subroutine, the run time was decreased to 48 seconds. 
With the completion of the update of the system code to more accurately reflect the GE design presented at SDR, and the conversion of the code from a design to a performance code, the only other modification required was the addition of stepping forward in time. This is currently done simply by inputting an end time and a time step. Figure 1 shows an overall flow chart for the OLM code. The first step is to input the system configuration data into the code. Table 3 gives a current listing of the input variables and their purpose, arranged by subsystem. Following the inputs the time is stepped, with the initial time step resulting in the time being zero, except for the silicon germanium thermoelectric material which is assumed to start with 1500 hours of time at temperature. Next, a reactor coolant outlet temperature is chosen. Then, the values are adjusted for each of the eight iteration variables. There are four variables for the main system and a similar four variables for the ACL. The four variables are the reactor thermal power, the reactor coolant temperature differential, the heat rejection subsystem fluid temperature differential, and the cold junction temperature of the thermoelectric material. With these eight variables chosen, along with the reactor temperature and all of the input parameters, then the overall system performance and mass is calculated at the given time step. The performance includes a thermal balance with all of the temperatures throughout the system, a hydraulic balance with all of the pressures throughout the system, and the electrical power output with an accounting of all power losses. Following these calculations all eight iteration variables are checked to determine if they are within one percent of their converged values. Again there are four checks each for the main system and for the ACL. These include the reactor thermal power level, the primary and secondary pressure drop compared to the pressure rise across the pump, and the heat rejected by the radiator versus the amount of waste heat throughout the system. If these are not all converged then new values are chosen for the iteration variables. If they have converged then the net electric power produced is compared with the desired electric power. If they are not within one-tenth of one percent and the reactor temperature is not up to it's maximum permissable then the reactor temperature is adjusted and the iteration variables must be reconverged. When the electric powers match, then the outputs are printed and the time is stepped forward. This process is repeated until the time has reached the total input mission duration and the code stops and the program is finished. A complete code listing is available in Reference 2.

Table 4 shows a sample output table for the case where no degradation occurs except for the thermoelectric materials and the impact of meteoroids and debris. It was assumed in this case that one of the secondary loops had failed at the beginning of the mission as the result of a meteoroid or debris impact. The result is run with a desired electric power output to the user of 100 kilowatts and a peak reactor temperature of $1375 \mathrm{~K}$. The output parameters in the table may be adjusted to whichever parameters are of interest. The data within the table is then transferred to a plotting program so that the data may be displayed in graphical form. Figure 2 presents the electrical power output available as a function of time. From the figure it is evident that the full 100 kilowatts is only available for the first four years of the mission, at which point in time the reactor outlet temperature has reached the maximum permissable temperature of 1375 Kelvin. Figure 3 presents the plot of reactor temperature as a function of time. Figure 4 shows how the thermoelectric material figure of merit decreases with time, from an initial value of $0.85 \times 10^{-3} \mathrm{~K}^{-1}$ to a value of 0.77 $x 10^{-3} \mathrm{~K}^{-1}$ at the end of a 7 year mission. Figure 5 shows the loss of heat pipes 
within the radiator as a result of meteoroid and debris impacts. By the end of 7 years a total of 524 out of 5448 heat pipes within the main heat rejection subsytem had been lost as a result of punctures. Figure 6 shows how the heat rejection coolant outlet temperature varies as a function of time. It increases both as a result of the reactor temperature increase and the loss of heat pipes. 


\section{SECTION 8}

\section{DEGRADATION PARAMETERS}

The (OLM) is intended to be a comprehensive collection of degradation models which will provide a temporal profile of important system parameters for the SP-100 Space Reactor Power System. The degradation models in turn represent the effects of numerous degradation mechanisms which contribute to the deterioration of performance for the nuclear and space subsystems. Failure Mechanisms Effects Analyses (FMEAs) were utilized as a starting point to determine the possible range of degradation mechanisms for both the nuclear and space subsystems. In most cases, the failure mechanism contributed to a situation where the system is forced to shutdown in rapid fashion and is not regarded as a degradation mechanism. The OLM, as it is currently envisioned, does not model transient effects and is a steady state performance model, therefore, effects relating to system failure are excluded for modeling purposes. However, where graceful effects could be identified, the failure mechanism was considered as a degradation mechanism. Other categories which prevent categorization of the failure mechanism as a degradation mechanism include failure mechanisms as they apply to re-entry, startup/thaw, etc. A survey of FMEA and similar documents resulted in the formation of 21 degradation mechanism modelling categories, hereafter called degradation models into which all degradation mechanisms may be classified. For purposes of the OLM, distilling of the degradation mechanisms into degradation modelling categories is the only rational way of handling the analysis and coding. The following section 1ists the 21 proposed degradation models for the OLM effort:

1) Primary heat transport hydraulic resistance (mechanisms relating changes in coolant flow area/friction factor/and other properties affecting flow.)

2) Radiation shielding degradation (shield deterioration leading to a change in the neutron and gamma shielding capability)

3) Fluid property changes (including infiltration of other materials and gases)

4) Thermal losses from primary loop (including thermal insulation degradation effects)

5) TEM pump electrical performance (including shorts, interconnect and busbar problems)

6) TEM pump magnetic performance (degradation of the magnet material due to temperature cycling and various chemical diffusive effects)

7) TE material property variations (effects due to dopant precipitation and alloying)

8) Meteoroid and debris environmental and damage model

9) Emissivity coating (degradation from meteoroid abrasion and atomic oxygen)

10) Secondary heat transport hydraulic resistance (counterpart to the primary hydraulic resistance model)

11) Electrode degradation (silicon and germanium sublimation, germanium diffusion, and tungsten carbide growth) 
12) Electrical shunt resistances in $T / E$ cell

13) Heat pipe degradation (pore clogging, contamination, etc.)

14) Bleed hole effects

15) Power conditioning and conversion power losses

16) Impact of nuclear radiation (performance impacts due to gamma and neutron exposure over time)

17) Heat exchanger thermal performance degradation

18) Bond deterioration in $T / E$ cell affecting thermal contact and electrical contact resistances. (probably done on a component basis, as with the electrode)

19) Environmental changes due to mission and location (including effects of atomic oxygen, plasma, meteoroids, comets, radiation)

20) Electrical interconnection degradation

21) Thermal bypass losses within $\mathrm{T} / \mathrm{E}$ cell

Each degradation model will address by priority of importance and effect the various mechanisms which come into that category. For example, there are 48 identified mechanisms categorized under model 1 (primary heat transport hydraulic resistance). An analysis will be performed to determine which of the 48 effects have the highest impact and priority of modelling. Similar analyses will be performed for the other degradation models. Impacts to the system by these mechanisms will be determined based on available test data and analyses. If no prior data is available, variation of parameters will be performed to determine the impact on the system. In situations such as these, placeholder subroutines will provide a marker to which additional information can be added as more experimental and analytical information is gathered.

Table 5 correlates the degradation mechanisms extracted from the nuclear, space subsystem, system, and environmental failure mechanisms lists into the above twenty-one degradation models.

With the emphasis on the effects of the degradation mechanisms, it is now possible to distill a relatively small number of degradation models from numerous degradation mechanisms. Rather than modelling hundreds, perhaps thousands of degradation mechanisms with little hope of proper organization and priority determination, it was found that grouping the numerous mechanisms into a manageable number of degradation models has made the job of OLM modelling tenable, tractable and more useful. This does not preclude the modelling of individual mechanisms, indeed many degradation mechanisms will be individually modelled within the degradation models. An example would be the electrode degradation model where the mechanism of silicon and germanium sublimation with it's effect on geometry and the effect of germanium diffusion and tungsten carbide growth will effect both the thermal and electrical contact resistances within the electrode. 


\section{PRELIMINARY DEGRADATION SENSITIVITIES}

In order to verify the proper operation of the code, determine where the code needs improvements, and assist in developing the priorities for future detailed degradation models, a series of parametric studies were made. A total of five major degradation parameters were selected. The parameters included the primary and secondary hydraulic resistance, the thermal and electrical contact resistances within the thermoelectric cells of the PCSS and TEM pump, and the radiator emissivity.

Figure 7 shows the power output available to the user as a function of time and primary loop hydraulic resistance. As the primary loop hydraulic resistance increases, the direct impact is that the primary mass flow rate must decrease to keep the primary pressure drop constant to match the pressure rise across the TEM pump. This impact is reflected in Figure 8 which shows the reactor fluid temperature differential as a function of time and hydraulic resistance increase. This shows that with a 208 per year increase in hydraulic resistance, the equivalent of a 3.6 times increase in pressure drop for a constant mass flow rate at the end of 7 years, the temperature drop across the reactor is increased by a factor of 1.7 with about a 78 decrease in electric power output. The fact that the temperature drop across the reactor increases with time even without any hydraulic resistance increase is a result of the decreasing TEM pump performance due to degradation of the thermoelectric materials.

Figure 9 shows the power output available to the user as a function of time and secondary hydraulic resistance. As the secondary hydraulic resistance increases, the direct impact is that the secondary mass flow rate must decrease to keep the secondary pressure drop constant to match the pressure rise across the TEM pump. This impact is reflected in Figure 10 which shows the radiator temperature differential as a function of time and secondary loop hydraulic resistance increase. This graph shows that with a 108 per year increase in the secondary loop hydraulic resistance, the equivalent of a 1.9 times increase in pressure drop for a constant mass flow rate at the end of 7 years, the temperature drop across the radiator is increased by a factor of 1.45 with about a 28 decrease in electric power output. Again, the reason that the temperature drop across the radiator increases with time even without any hydraulic resistance increase is because of the decreasing TEM pump performance. An additional effect which occurs with an increasing temperature drop across the radiator is that the temperature of the fluid leaving the radiator will decrease. This effect is shown in Figure 11. If the hydraulic resistance is maintained at a constant, the fluid outlet temperature will increase as a result of the loss of heat pipes due to damage from meteoroid and debris impact. However, if the hydraulic resistance increase is greater than 108 per year, then the radiator fluid return temperature will decrease. The impact of this is that now some of the coldest radiator heat pipes become sonically limited and won't be able to reject heat over their entire condensor length and the system performance will decrease more rapidly. However, the current OLM code doesn't allow the code to run after the heat pipes can't carry all of the heat that is desired. This pointed out an area where the olM must be improved next year. The heat rejection subsystem needs to be divided into more segments and if the heat pipes within one segment are power limited then, the condensor needs to be shortened to an effective length which allows the heat pipe to operate properly.

Figure 12 shows the power output available to the user as a function of time and thermal contact resistance degradation rate. As the thermal contact resistances 
between the thermoelectric cell components within the PCSS and TEM pump increase, the direct impact is that the parasitic temperature drop across the cell will increase. This impact is reflected in Figure 13 which shows the PCSS parasitic temperature drop as a function of time and thermal contact resistance increase. This shows that with a 308 per year increase in thermal contact resistance, the equivalent of 6.3 times increase at the end of seven years, the parasitic temperature drop across the cell is increased by a factor of 1.13 with about a 2.38 decrease in electric power output.

Figure 14 shows the power output available to the user as a function of time and electrical contact resistance degradation rate. As the electrical contact resistance between the silicon germanium and graphite within the thermoelectric cells within the PCSS and TEM pump increase, the direct impact is that the parasitic electric power losses within the cell will increase. This impact is reflected in Figure 15 which shows the PCSS electric power losses as a result of the contact resistances as a function of time and electrical contact resistance increase. This shows that with a 20 per year increase in electrical contact resistance, the equivalent of 3.6 times increase at the end of seven years, the parasitic electric power loss is increased by a factor of 2.6 . The equivalent effect within the TEM pump results in a decrease in pumping power for both the primary and secondary loops. Figure 16 shows the effect on the fluid temperature differential across the reactor as a function of time and electrical contact resistance degradation rate. The reactor temperature difference was increased by $6 \%$ for the 3.6 times increase in electrical contact resistance. The radiator temperature difference was similarly increased by about 108 from the same increase in electrical contact resistance. The total impact on the electrical power output available to the user is a decrease of 158 for the 3.6 times increase in electrical contact resistance. This impact was essentially evenly divided between the decrease in PCSS performance and the decrease in pumping power.

Figure 17 shows the power output avallable to the user as a function of time and radiator emissivity degradation rate. As the radiator emissivity decreases, the direct impact is that radiator temperature increases. This impact is reflected in Figure 18 which shows the radiator fluid exit temperature as a function of time and radiator emissivity increase. This shows that with a 38 per year decrease in radiator emissivity, the equivalent of decreasing the emissivity from 0.85 to 0.69 at the end of seven years, the radiator temperature increased by 27 $\mathrm{K}$. This $27 \mathrm{~K}$ increase in radiator temperature results in a decrease in the available temperature difference across the PCSS with a resultant 12 decrease in electric power output.

In conclusion, as a result of the sensitivity studies, I am confident that the OLM code does indeed work properly over a wide range of degradation conditions. However, as indicated above, I have determined that the heat rejection subsystem will need to be upgraded in order to properly account for degradation which results in lower radiator temperatures or a decrease in heat pipe performance. In addition, as a result of the sensitivity studies which have been performed, I believe that radiator emissivity degradation and degradation of the bond between silicon germanium and the graphite electrode are two of the more important degradation models which should be developed in the near term. 
SECTION 10

PLANS

The activities planned for FY' 91 year are all related to the development of additional detailed degradation models for inclusion in the OLM. The first activity is to identify the potential range of variation due to the various degradation mechanisms and the available data for each mechanism. These variations will be combined into an overall potential degradation associated with each identified degradation model. Then their impact on system performance will be calculated with the OLM. Based on this information, the degradation models will be prioritized for development. The remainder of the year will be spent on developing the detailed degradation models and incorporating them into the code. In addition, the heat rejection subsystem will be upgraded in order to accurately predict system performance as it degrades.

Based on the preliminary sensitivity studies, the following three degradation models have been identified for early development: 1) radiator emissivity, 2) primary loop hydraulic resistance, and 3) electrode degradation. The radiator emissivity degradation model will examine the deterioration of the high emissivity coating by abrasion from the impact of meteoroids and debris, as well as the effect of plasma and atomic oxygen. The primary loop hydraulic resistance model will estimate the impact of fuel swelling and fission gas generation on fuel clad creep and the subsequent change in core cooling channel areas. In addition, it will allow for the blockage of the gas separator by deposition of precipitates in the lithium, and changing of the plumbing friction factor from erosion or chemical interactions. The electrode degradation model would include the impact of silicon and germanium sublimation on the geometry of the cell, the effect of germanium diffusion and subsequent loss from the bond of graphite to silicon germanium, and the impact of tungsten carbide growth in the tungsten to graphite bond. The electrode degradation model will result in changing both the electrical and thermal contact resistance with time.

The changes that will need to be made to the heat rejection subsystem performance calculation are twofold. First, the radiator needs to be divided into more segments. Currently, the radiator only has two segments: one segment to account for the heat pipes associated with the flow going out to the tip of the radiator and the second segment to account for the heat pipes associated with the return flow. All of the heat pipes in each section are assumed to have the same average length and temperature. The code needs to subdivide the radiator into more segments, each of which will have a different average heat pipe length, temperature, and view factor associated with it. The second modification that needs to be made is to allow the effective heat pipe condensor length to be reduced if the heat pipe is incapable of carrying the full amount of heat that the pipe could reject. This would occur either if the evaporator temperature is too low and the pipe becomes sonically limited, or if the heat pipe itself has degraded so that either the wick pore size has changed or some inert gas has been generated. 
system outputs

$$
\begin{aligned}
100.06 & \text { kilowatts electric } \\
5332.5 & \text { kilograms-system mass } \\
7 . & \text { years-current time } \\
10 . & \text { years-mission design lifetime }
\end{aligned}
$$

reactor subsystem

$$
\begin{array}{rl}
1375.4 & k \text {-outlet temperature } \\
1319.4 & k \text {-inlet temperature } \\
2.33 & \text { mw--outlet thermal power }
\end{array}
$$

shield subsystam

$0.18+14 \mathrm{n} / \mathrm{cm} 2-$-payload dose limit for neutrons

$0.5 E+06$ rads--payload dose limit for gama photons

auxialiary cooling subsytam

$$
\begin{array}{r}
0.037 \text { mwt--thermal power } \\
1.16 \text { kwe-net electrical power }
\end{array}
$$

heat transport subsytem

$$
\begin{aligned}
& 1375.4 \mathrm{k} \text {-inlet temperature } \\
& 1336.3 \mathrm{k} \text {-outlet temperature at heat exchanger surface } \\
& 10.02 \text { k1lograms/second--primary loop mass flow rate } \\
& 10.31 \mathrm{kilograms/second--secondary} \mathrm{loop} \mathrm{mass} \mathrm{flow} \mathrm{rate} \\
& \text { 12. total number of pumps } \\
& 1 \text { number of secondary loops failed } \\
& 24.0 \text { cm--active e.m. pump length } \\
& \text {.287E+05 pa--total primary loop pressure drop } \\
& .286 \mathrm{E}+05 \text { pa--total primary side pressure rise } \\
& \text {.325E+05 pa-ctotal secondary loop pressure drop } \\
& \text {.314E+05 pa--total secondary side pressure rise } \\
& .249 E+06 \text { watts-heat taken from primary loop } \\
& .224 E+06 \text { watts-heat rejected into secondary loop } \\
& .650 \mathrm{E}+05 \text { wetts--thaw heat into secondary loop }
\end{aligned}
$$

power conversion subsystem

$$
\begin{aligned}
& \text { SDR SiGe/GaP properties used } \\
& 2336.3 \mathrm{k} \text {-hot shoe inlet temperature } \\
& 1304.3 \mathrm{k} \text {--hot junction temperature } \\
& 865.4 \mathrm{k} \text {--cold junction temperature } \\
& 835.3 \mathrm{k} \text {--cold shoe outlet temperature } \\
& 1155.7 \text { kilowates-net acl electric power } \\
& \text { 105.1 kilowatts-net e.0.1. electric power } \\
& 0.6915 \text { cantimaters--leg langth } \\
& 0.2080 \text { square centimeters--couple area } \\
& 0.6371 \text { area ratio of } n \text { p-legs } \\
& 1.3035 \text { ratio of load to couple intermal resistance } \\
& 0.1432 \text { volts--thermocouple voltage } \\
& 2.8819 \text { amperes--thermocouple current } \\
& 38.13 \text { milliohms--total couple internal resistance } \\
& \text {.773E-03 inverse kelvin--material figure of merit } \\
& 0.4128 \text { watts--power per couple } \\
& 6.864 \text { square centimeters--cell area } \\
& 1.146 \text { volts--thermoelectric cell voltage } \\
& 11.528 \text { amperes--thermoelectric cell current } \\
& 13.21 \text { watts--cell electric power } \\
& 0.046 \text { square meters--TCA area }
\end{aligned}
$$


Table 1. SP-100 OLM Results for SDR Baseline (continued)

205.5 volts--thermoelectric h.x. voltage

46.1 amperes-thermoelectric $h . x$. current

9.472 kilowatts--h.x. electric power

heat rejection subsystem

104.2 square meters--total exterior surface area

0.85 radiator emissivity

848.2 k-fluid inlet temperature

$796.2 \mathrm{k}$-fluid outlet temperature

$250.0 \mathrm{k}$-temperature of space

18587.3 pa--total lluid pressure drop

104.2 square meters--deployed exterior surface area

108.1 square meters--black body area per G.E. method

5.91 meters--deployed panel conical length

0.980 view factor from exterior surface to space

0.457 View factor from interior surface to space

5448 number of heat pipes in the conical section

145 number of heat pipes lost due to debris

91 number of heat pipes lost due to neteors

0.03076 effective fraction of hat pipe area loss due to m\&d

0.152 meters--evaporator length

0.000 meters-adiabatic length

0.572 meters--average condenser length

0.502 kilowatts-required left conical heat pipe power

0.432 kilowatts-required right conical heat pipe power

1.350 kilowates-left conical heat pipe power limit

0.925 kilowates-right conical heat pipe power limit

$.223 \mathrm{E}+07$ watts-reject heat from deployed area

power conditioning subsystem
3.72
kilowatts--cabling power consumption
1.29 kilowatts--pec power consumption
5.01 kilowatts-total perc electric power loss 
system outputs

$$
\begin{aligned}
100.01 & \text { kilowatts electric } \\
5331.3 & \text { kilograms--system mass } \\
7 . & \text { years-current time } \\
10 . & \text { years-mission design lifetime }
\end{aligned}
$$

reactor subsystem

k--outlet temperature

$\mathrm{k}$--inlet temperature

mwt--outlet thermal power

shield subsystem

n/cm2--payload dose limit for neutrons

$0.5 E+06$

rads-payload dose limit for gamma photons

auxialiary cooling subsytem

0.037 mut--thermal powar

1.17 kwe--net electrical power

heat transport subsytem

1386.8

1347.6

10.02

10.29

12.

k--inlet temperature

$k$--outlet temperature at heat exchanger surface

kilograms/second--primary loop mass flow rate

kilograms/second--secondary loop mass flow rate total number of pumps

1 number of secondary loops failed

24.0 cm--active o.m. pump length

.286E+05 pa--total primary loop pressure drop

$.286 \mathrm{E}+05$ pa--total primary side pressure rise

-314E+05 pa--total secondary loop pressure drop

- $314 \mathrm{E}+05$ pa--total secondary side pressure rise

$.2495+06$ watts--heat taken from primary loop

$.223 \mathrm{E}+06$ watts-heat rejected into secondary loop

$.650 E+05$ watts--thaw heat into secondary loop

power conversion subsystem

SDR SiGe/GaP properties used

$1347.6 \mathrm{k}$-hot shoe inlet temperature

$1315.6 \mathrm{k}$-hot junction temperature

$878.2 \mathrm{k}$--cold junction temperature

$848.1 \mathrm{k}$--cold shoe outlet temperature

2171.7 kilowatts-net acl electric power

105.0 kilowates-net e.0.1. electric power

0.6915 centimeters-leg length

0.2080 square centimeters--couple area

0.6371 area ratio of $n$ \& p-legs

1.3046 ratio of load to couple internal resistance

0.1430 volts--thermocouple voltage

2.8840 amperes--thermocouple current

38.02 milliohms--total couple internal resistance

.777E-03 inverse kelvin-material figure of merit

0.4125 watts--power per couple

6.864 square centimeters-cell area

1.144 volts-thermoelectric cell voltage

11.536 amperes--thermoelectric cell current

13.20 watts--cell electric power

0.046 square meters--TCA area 
Table 2. SP-100 OLM EOL Performance (continued)

205.3 volts--thermoelectric h.x. voltage

46.1 amperes--thermoelectric h.x. current

9.466 kilowatts-h.x. electric power

neat rejection subsystem

104.2 square meters--total exterior surface area

0.85 radiator emissivity

$861.0 \mathrm{k}$--eluid inlet temperature

808.9 k--1uid outlet temperature

$250.0 \mathrm{k}$--tomperature of space

18550.7 pa-cotal fluid pressure drop

104.2 square meters--deployed exterior surface area

100.8 square meters--black body area per G.E. method

5.91 meters--deployed panel conical length

0.980 view factor from exterior surface to space

0.457 viow factor from interior surface to space

5448 number of heat pipes in the conical section

732 number of heat pipes lost due to peteors 8 debris

0.09540 effective fraction of heat pipe area loss due to med

0.152 meters-evaporator length

0.000 meters-adiabatic Iength

0.572 meters-maverage condenser length

0.552 kilowatts-required left conical heat pipe power

0.477 kilowatts-required right conical heat pipe power

1.575 kilowates--left conical heat pipe power limit

1.105 kilowatts-right conical heat pipe power limit

$.2235+07$ watts-reject heat from deployed area

power conditioning subsystem

3.73 kilowatts--cabling power consumption

1.29 kilowatts--pce power consumption

5.02 kflowates--total pere electric power loss 
Table 3. SP-100 OLM Inputs

temp=reactor output temperature (K) (initialization)

elagopt=flag for iteration to desired elect. power (1.--if want) pwroutudesired net electric power to user (kilowatts)

despwrmreactor design thermal power (megawatts)

dtime-time step (years)

ttime-total Iifetime of system in space (years)

tempmax-maximum reactor outlet temperature (K) DEGRADATION PARAYIETERS

coefppd=coefficient for increase in primary pressure drop (t per year) coefspd=coefficient for increase in secondary pressure drop (t per year) coefemismcoefficient for decrease in radiator enissivity (t per year) coefecn-coef. for modifying the electrical contact resistance $(z / y r)$ coefrcnacoef. for modifying the thermal contact resistance $(z / y r)$ coefpore-coefficient for degradation in heat pipe pore size REACTOR \& CONIROLS

rctpwrminitial estimate of reactor thermal output power (mwt). ditrctiminitial estimate of reactor temperature increase (k) rctrldaratio of reactor length to diameter (diam/hrv)

rictot=total mass of reactor instrumentation controls thawpw power to heat rejection from thaw heat pipes (watts) shadegrshield half-angle (degrees)

bum-separation distance from reactor to reference dose plane (m) dpl=diameter of reference dose plane (m) din=neutron dose limit at reference plane $(n / c m * \pm 2)$ digngama dose limit at reference plane (rads)

Leactive e.m. pump length (Cm) HEAT TRANSPORI

lagl-flag to $f$ ix pump length of optimize (1--fixed length) npumps=number of e.m. pumps

nioopenumber of secondary loops failed aspect=primary duct aspect ration (height/width) fobmatio width/thickness, connecting bus heightp-height of pump primary duct I.D. (Cm) heightsmeight of pump secondary duct I.D. (Cm) whaw-mass of thaw assembly, (kilograms)

ifluidp-designates working fluid in heat transport hx i.e. 1-11, 2-na, 3-k, 4-hg, 5-water, 6-nak, 7-he

isolidpmdesignates material used for heat transport $\mathrm{bx} i . e$. 1-w, 2-nb, 3-zr, 4-304/316 S.S., 5-grahpite, 6-beryllium, 7-titanium hxwall-hot side heat exchanger wail thickness, meters thipheight of interior passage within hot h.x., meters dinttrp=factor multiplied to heat transport piping diameter to vary ifluids-designates working fluid in heat transport hx i.e. 1-1i, 2-na , 3-k, 4-hg, 5-water, 6-nak, 7-he

isolids=designates material used for heat transport $\mathrm{bx}$ i.e. 1-W, 2-nb, 3-2r, 4-304/316 5.5. ,5-grahpite, 6-beryliium, 7-titanium ditseci=initial estimate of temperature delta in secondary loop (k) dihttrs=factor multiplied to heat transport piping diameter to vary 
tids=cold side heat exchanger channel interior width, meters tods=cold side heat exchanger channel outside width, meters this=cold side heat exchanger channel interior height, meters thiks=cold side heat exchanger total thickness of one layer, meters POWER CONVERSION

elemellag to determine type of $t / e$ properties

1. e. 1-Standard SiGe 2-S1Ge/GaP (GFS data Irom SDR)

imprefraction multiplied by thermal conduc. to improve $z$ conlenmcouple length, meters

lenop-ilag for optimization of couple resistance ratio

1: optimize mo for maximum performance

2: keep mo elxed

3: vary mo to obtain desired systen voltage

voltsys=desired system voltage out of pcss

mo-ratio of internal couple to external load resistances

aratiomratio of $n$ \& $\mathrm{leg}$ cross-sectional araa

ncellw-number of cells across the width of the heat exchanger

ncellhwnuber of cells along the length of the heat exchanger acoup $t /$ couple area $n+p(m \neq * 2)$

petring=number of parallel strings within each pack

nolay number of layers within heat exchanger

cells-number of series of couples per cell

cellp=number of parallel couples per cell

parlaymumber of TCAs within $h . x$. which are in parallel

thstrap-thickness of interconnect strap, meters

restrap-electrical resistivity of strap, ohm-cm

ihs-number of interfaces in the hot stack $\mathrm{bx}$ outside surface is

$\# 1$ and the hot junction interface is the last

1cs-number of interfaces in the cold stack cold junction interface is $\$ 1$ and the heat pipe outside surface is last

itconmumber of thermal contact resistances

ieconmumber of electrical contact resistances

ecntctomarray of up to 8 electrical contact resistances (ohm-cm2) These are the values which apply at beginning of life ecntcto(1)=contact for hot side n-leg siee ecntcto $(2)$ =contact for hot side p-Ieg sice ecntcto (3) =contact for cold side n-leg sice ecntcto (4)=contact for cold side p-leg sice ecntcto (5) =contact for hot side n-leg grahpite ecntcto (6)=contact for hot side p-leg graphite ecntcto (7)=contact for cold side n-log graphite ecntcto $(B)=$ contact for cold side $p$-leg graphite

rcntctomarray of up to 24 thermal contact resistances (cm**2-k/w) These are the values which apply at beginning of life rentcto (odd) =hot side contact resistances rontcto (even) mcold side contact resistances

hsmarrary of hot shoe characteristics

$h s(i, 1)=$ function of $i$ th layer; 1 module insulator

2=compliant pad

$3=c e l 1$ insulator

4 melectrical connector

5 moxygen permeation barrier 


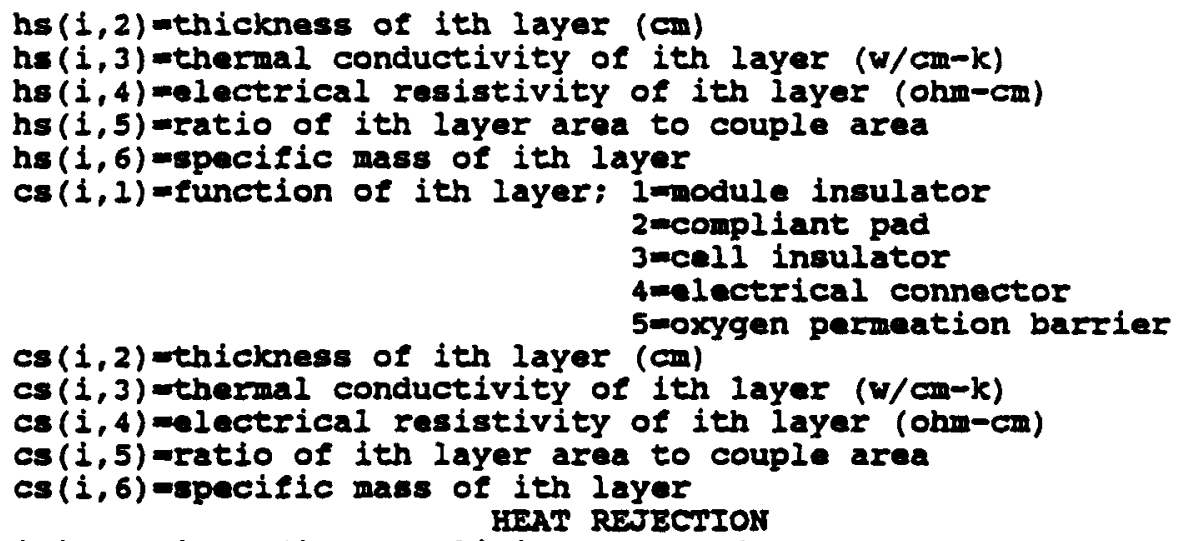

dimitmaximum diameter limit on stowed systam (m) hlimitmaximum stowed length of system (u) npolygunumber of sides on the erustum polygon dppnil-deployed radiator length (meters) tspacemefective temperature of space (k) eradanissivity of radiator configudeployed radiator configuration--1: trapezoidal panels
2: rectangular panels alt=altitude above earth surface (kilometers) flagdb-ilag to select debris environments (0.) spec. (1.) Kessler llagmet=flag to select mode of runing damage model: 0 : debris only 1: meteoroids only 2: both meteoroids and debris

ducting directly in contact with the radiator heat pipes isldinrmelag to select the duct liner material 7-titanium isldbrreflag to select the duct barrier material 8-silver islddt=elag to select the duct armor material 6-beryllium detiwnduct internal width (w) detih-duct internal height (II) det Inreduct internal liner equivalent thickness for armor material (m) detbrr-duct barrier equivalent armor thickness between the liner and armor of armor material (m)

dctarmhinduct armor material thickness adjacent to heat pipes (m) dctarmsmduct armor material thickness on the strong back side (m) detercf-fraction of effective duct area on flxed section radiating detfrcdefraction of effective duct area on deployed section radiating isldrtn=elag to select the piping material in the return Iine diartn=diameter of the retum line piping (m) walrtnwall thickness of the return line bypasfre-fraction of flow in secondary loop bypassed Igfixed=flag to indicate if want a fixed radiator (1: no) these are inputs to describe the ixed radiator heat pipes: Ilgothp=lag to by-pass the heat pipe subroutine in the fixed radiator elgner-elag for detailed input print out 0 -no output, I-detail output elghfr=flag for detailed output print out 0-no output, 1-detail output alngfreadibatic length (m) 
Table 3. SP-100 OLM Inputs (continued)

fermelag to select heat pipe working fluid 9-potassium mlermflag to select heat pipe and wick material 9-titanium scmser-heat pipe wick screen mesh ctwrerenumber of layers of screen mesh in the wick artfrf=eraction of heat pipe $x$-section used for arteries artnof number of heat pipe arteries in fixed radiator heat pipes fracsrfufraction of heat pipe evaporator suface transfering heat rolhpf=round to " $D$ " shaped heat pipe circumference correction for mass(fix bndifrmumber of bends in the eixed radiator heat pipes b1-3frmbend angle for bends $1-3$ (radlans) rr-3 1 rmbend radii of bends $1-3$ (II) loctrr-location of single bend in adiabatic section (m) hpodfr=fixed radiator heat pipe $0 . d$. (m) tkhper-fixed radiator heat pipe wall thickness (m)

ahpidf-total flow area inside the fixed radiator heat pipe (sq. m) these inpute are for the eixed radiator

vflfr-radiator exterior surface view factor vf2fr-radiator interior surface view factor thkffr-itn thickness (m)

mater-radiator material flag 6-beryllium

finlnf-fixed radiator in length (m)

aacpnl-area of access panels $(m * * 2)$ not used to reject beat these are inputs to describe the deployed radiator heat pipes elgodhperlag to by-pass the heat pipe subroutine in the doployed radiator alngdradibatic length (m) fareilag to select heat pipe working eluid 9-potassium mldrelag to select heat pipe and wick material 9-titanium scinsdr=heat pipe wick screen mesh ctwrdr-number of layers of screen meah in the wick arterdefraction of deployed heat pipe $x$-section used for arteries artnod=number of arteries in the deployed radiator heat pipes fracsrd=fraction of evaporator surface transfering heat redhpd=round to "D" shaped heat pipe circumference correction for mases (deployed)

bndndrenumber of bends in the deployed radiator heat pipes

b1-3dr-bend angle for bends $1-3$ (radians)

rr1-3drebend radil of bends 1-3 (m)

loctdrelocation of ingle bend in adiabatic section (m)

hpoddradeployed radiator heat pipe $0 . d$. (m)

thhpdredeployed radiator heat pipe wall thickness (m)

ahpiddwtotal flow area inside the deployed radiator heat pipe (sq. m) these inputs are for the doployed radiator

vfldr-radiator exterior surface view factor

ve2dreradiator interior surface view factor

thkedrefin thickness (ii)

matdradiator matorial flag 6-beryllium

Inlnd-deployed radiator in length (m)

probfr-prob. fixed heat pipe failures will not exceed calculated value

probdr-prob. deployed heat pipe failures will not exceed calculated value

armtkfmarmor thickness on fixed heat pipes (m)

armtkd=armor thickness on deployed heat pipes (m)

isldarm-armor material on all heat pipes (6-berylilum)

probdct-duct design reliability for meteoroid and space debris 
facudefraction of heat rejected from failed fixed heat pipe facuddefraction of heat rejected from failed deployed heat pipe STRUCTURES

wbmfxd=fixed mass of the boom independent of length ( $\mathrm{kg}$ ) rhobum=density of boom material ( $\mathrm{kg} / \mathrm{m} \neq * 3$ ) cbos=boom adjustment factor $(m * * 2)$ bummi-boom mass moment of inertis PCCED

elgcbl=elag to optimize cable diameter (1. to optimize) acp=cool section power cable cross-sectional area, cm $\star 2$ acpht=hot section power cable cross-sectional area, cm**2 ACL

dltpachot side temp. difference in acl 1000 , Kelvin ditsacwcold side temp. difference in acl loop, Kelvin gacl=reactor thermal power into acl 100p, Hegawatts (initial) msacl=secondary mass flow rate in the acl loop, $\mathrm{ks} / \mathrm{sec}$ (initial) FLAGS FOR DEYAIIED PRINHOUTS

flagit=flag to print out iteration information (1.--if want) flagmas=flag for detailed mass printout (1.--if want printout) flagnuk=flag for detailed nuclear subsytem printout (1.--if want) flagpcerflag for detailed pcss printout (2.--if want printout) flaghrs=flag for detailed hrss printout (1.--if want printout) flgrct=flag for detail reactor output 0-no output 1-output Ilagem=ilag for detailed.$m$. pump printout

Ilgrdf=rlag for detail print out i-detajl print out,0-no print out flgndr=ilag for detailed input print out 0 no output, 1-detail output elghdr=elag for detailed output print out 0 -no output, 1-detail output ilgrdd=flag for detail print out 1 -detail print out, 0 -no print out ldet=flag for detail pec print out 1-print out 0 -no print out 
Table 4. OLM Output Versus Time

$\begin{array}{rrrrrrr}\text { time } & \begin{array}{c}\text { system } \\ \text { power } \\ \text { (Kwe) }\end{array} & \begin{array}{c}\text { reactor } \\ \text { temp } \\ \text { (Kelvin) }\end{array} & \begin{array}{c}\text { reactor } \\ \text { power } \\ \text { (Mwt) }\end{array} & \begin{array}{c}\text { z-value } \\ \text { (1/K) }\end{array} & \begin{array}{c}\text { radiator } \\ \text { temp } \\ \text { (Kelvin) }\end{array} & \begin{array}{r}\text { damage } \\ \text { (holes) }\end{array} \\ 0.00 & 100.05 & 1356.39 & 2.31 & 0.850 E-03 & 790.80 & 0 \\ 0.50 & 99.98 & 1359.07 & 2.30 & 0.828 E-03 & 790.39 & 52 \\ 1.00 & 99.95 & 1360.77 & 2.30 & 0.818 E-03 & 790.31 & 92 \\ 1.50 & 100.01 & 1364.90 & 2.30 & 0.808 E-03 & 792.23 & 130 \\ 2.00 & 99.94 & 1366.53 & 2.30 & 0.801 E-03 & 792.65 & 167 \\ 2.50 & 99.94 & 1368.59 & 2.31 & 0.795 E-03 & 793.48 & 204 \\ 3.00 & 99.94 & 1370.61 & 2.31 & 0.791 E-03 & 794.50 & 240 \\ 3.50 & 99.95 & 1372.63 & 2.31 & 0.788 E-03 & 795.63 & 277 \\ 4.00 & 99.90 & 1374.57 & 2.31 & 0.785 E-03 & 796.60 & 312 \\ 4.50 & 99.72 & 1375.00 & 2.31 & 0.782 E-03 & 796.89 & 348 \\ 5.00 & 99.18 & 1375.00 & 2.31 & 0.780 E-03 & 797.51 & 384 \\ 5.50 & 98.66 & 1375.00 & 2.30 & 0.777 E-03 & 797.94 & 418 \\ 6.00 & 98.16 & 1375.00 & 2.30 & 0.774 E-03 & 798.51 & 454 \\ 6.50 & 97.69 & 1375.00 & 2.29 & 0.772 E-03 & 798.97 & 489 \\ 7.00 & 97.20 & 1375.00 & 2.29 & 0.770 E-03 & 799.54 & 524\end{array}$


Table 5. Degradation Mechanisms Categorized Into Degradation Models

\author{
Degradation Mechanisms Categorized Into Degradation Models \\ PRIMARY HEAT TRANSPORT HYDRAUTIC RESISTANCE \\ Break off of blockage grards in nuclear reactor core by thermal \\ creep causes plugging in core flow area \\ Coolant erosion of orifice holes \\ Particulates plug orifice holes \\ Hydrogen bubbles plug orifice holes \\ swelling due to creep in honeycomb changes flow area \\ Holding stud cracks due to creep-fatigue affecting coolant path \\ cladding corrosion effects of flowing $\mathrm{Li}$ and particles enter \\ coolant path \\ Re barrier corrodes causing coolant to absorb particles \\ Fission products leach out and enter $\mathrm{Li}$ \\ Carbon transported in coolant \\ B4C enters coolant due to swelling and interference with thimble \\ Liner breached and B4C enters coolant \\ Fuel swelling cladding leaks \\ clad creep \\ clad dilation due to gas pressure \\ Clad hot spot (autocatalytic) \\ High tuel swelling load due to clad dilation \\ Gas pressure clad runaway \\ Thermal gradient autocatalytic pin bowing \\ Loose wire-pin spacing hot spot \\ Scratches in honeycomb during assembly \\ wireless pins- effect of hot spots
}


Table 5. Degradation Mechanisms Categorized Into Degradation Models (continued)

PwC-11 Irradiation Swelling

Ii corrosion in piping

Pipe collapse

PWC-1I thermal creep causes deformation in pipe

Various failures within gas separator/accumulator all relating to primary loop hydraulics

RADIATION SHTEIDING DEGRADATION

Beo cracking due to thermal shock (reflectors)

Beo dissociation, reflector integrity

oxidation effects due to BeO dissociation on reflectors

Beo swelling affecting reflectors

FIUID PROPERTY CHANGES

He gas buildup reduces specific heat of $\mathrm{LI}$

Gas bubbles on pipe wall

THEREAAL LOSSES FROY PRIMLARY LOOP

Thermal insulation removed by atomic oxygen

II and $R$ leaks between foil layers in insulation

Emissivity of insulation foil increased

TEM PUNP ELECTRICAL PERFORMANCE

Various electrical failures within TaU pump dealing with grounding or shorting due to degraded primary or secondary flow

TEX pump busbar degradation effects

TEM PUMP MAGNETIC PERPORMANCE

TEM Pump magnetics degradation effects such as curie temperature exceeded, magnet fracture/thermal cycling, diffusion of $\mathrm{Cr}, \mathrm{Fe}$, Co into lithium, etc. 
Table 5. Degradation Mechanisms Categorized Into Degradation Models (continued)

T/E MATERIAL PROPERTY VARIATIONS

T/E material resistivity increase due to dopant loss

T/E material Seebeck coefficient decrease

T/E matorial vaporization or diffusion

Reduced carrier concentration

Reduced carrier mobility

Increased polar or bipolar electronic components

METEOROID AND DEBRIS DAMAGE MODEL

Natural and man made mechanisms including asteroidal and cometary byproducts, number of rocket launches per year, number of collisions in space but largely a probabilistic model with a mechanistic damage model for penetration.

EMISSIVITY COATING

Behavior of coatings subject to temperature, space environment

including atomic oxygen, plasma, radiation, meteoroids and debris.

SECONDARY HEAT TRANSPORT HYDRAULIC RESISTANCE

Counterpart to primary system hydraulics.

ELECTRODE DEGRADATION

Bond failures due to embrittlement, grain growth, corrosion, kirkendal voiding, diffusion, evaporation, etc.

ELECTRICAI SHUNT RESISTANCES WITHIN T/E CELI

Material evaporation and redeposition, insulation integrity lost, etc.

HEAT PIPE DEGRADATION

Pore size changes, wick clogging, weld failures, meteoroid/debris impingement, sonic limiting due changes in operating conditions. 
BLEED HOLE CHANGES

clogging by impurities in heat transport system, erosion cause pressure drop and thermal conditions to change as function of time

POWER CONDITIONING POWER IOSSES

Deterioration in cabling, connectors, ICs, and other components lead to power loss over time.

IMPACT OF NUCLEAR RADIATION

Mechanisms speciflcally addressing the effect of gamma, neutron and other radiation on sensitive components within sp-100.

\section{HEAT EXCHANGER IHARUAI DEGRADATION}

Including all mechanisms which affect the thermal performance of the heat exchangers including film coefficient changes due to contaminants in heat exhanger operating fluid, losses of heat pipes, sonic limiting, loss of loop.

BOND DETERIORATION (GENERAI)

All mechanisms associated with thermal contact and electrical contact resistances such as those that exist in compliant pads, high voltage insulator heat exchanger interface, glass interfaces, heat pipe duct interfaces. Exaples of these mechanisms include embrittlement, corrosion, Rirkendal voiding, diffusion.

ENVIRONRUATPI CHANGES WITH MISSION AND IOCATION MODEIS

Includes atomic oxygen interaction mechanisms, plasma interaction mechanisms, meteoroid/debris interaction models, interplanetary models for radiation and electromagnetics.

ELECTRICAL INTERCONNECTION DEGRADATION

Resistance increases due to poor contact, axial glass degradation, interleg shorts, T/E material vaporization causing deposition of conductive matexials, strap corrosion, material grain growth, embrittlement all are possible mechanisms within this degradation model. 
Table 5. Degradation Mechanisms Categorized Into Degradation Models (continued)

THERYAL BYPASS LOSSES WITHIN T/E FOR POWER CONVERTER, ACL AND TEM PUMIP

This category includes machanisms associated with the thermal power which bypasses the $T / E$ element. There is normal bypass associated with radiation and conduction but conditions may change which cause the bypass loss to increase. Some mechanisms associated with the Increase in bypass $108 \mathrm{~s}$ include the deposition of vaporized materials which cause increased thermal conductive losses to occur, a degradation in the thermal insulators (glass) by chemical means or mechanical means (cracks, diffurion of undesireable materials atc.), and a change in the overall amiseivity where radiation transfers heat irom the hot side to the cold side. 


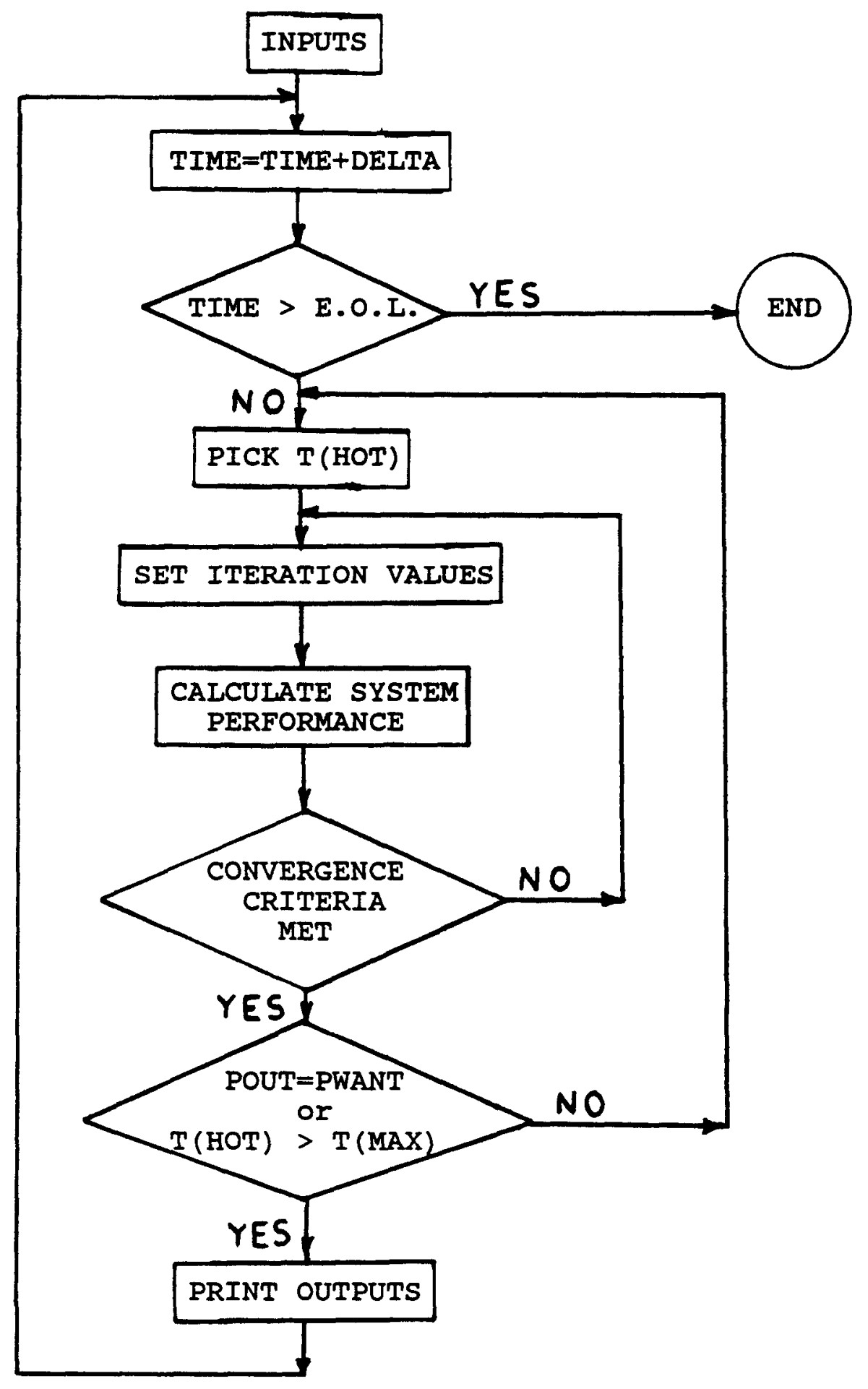

Figure 1. OLM Flow Chart 


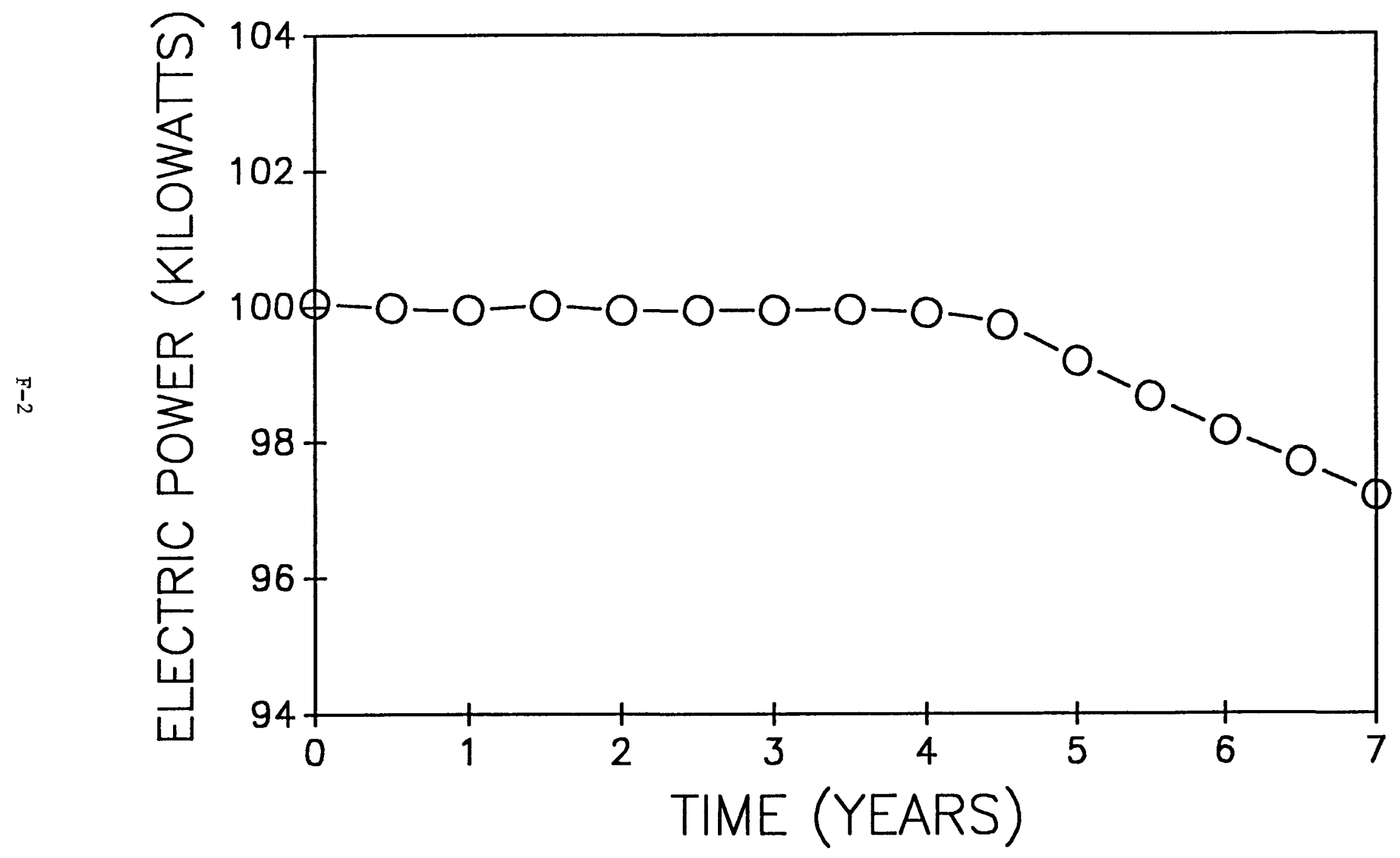

Figure 2. Baseline Electric Power vs Time 


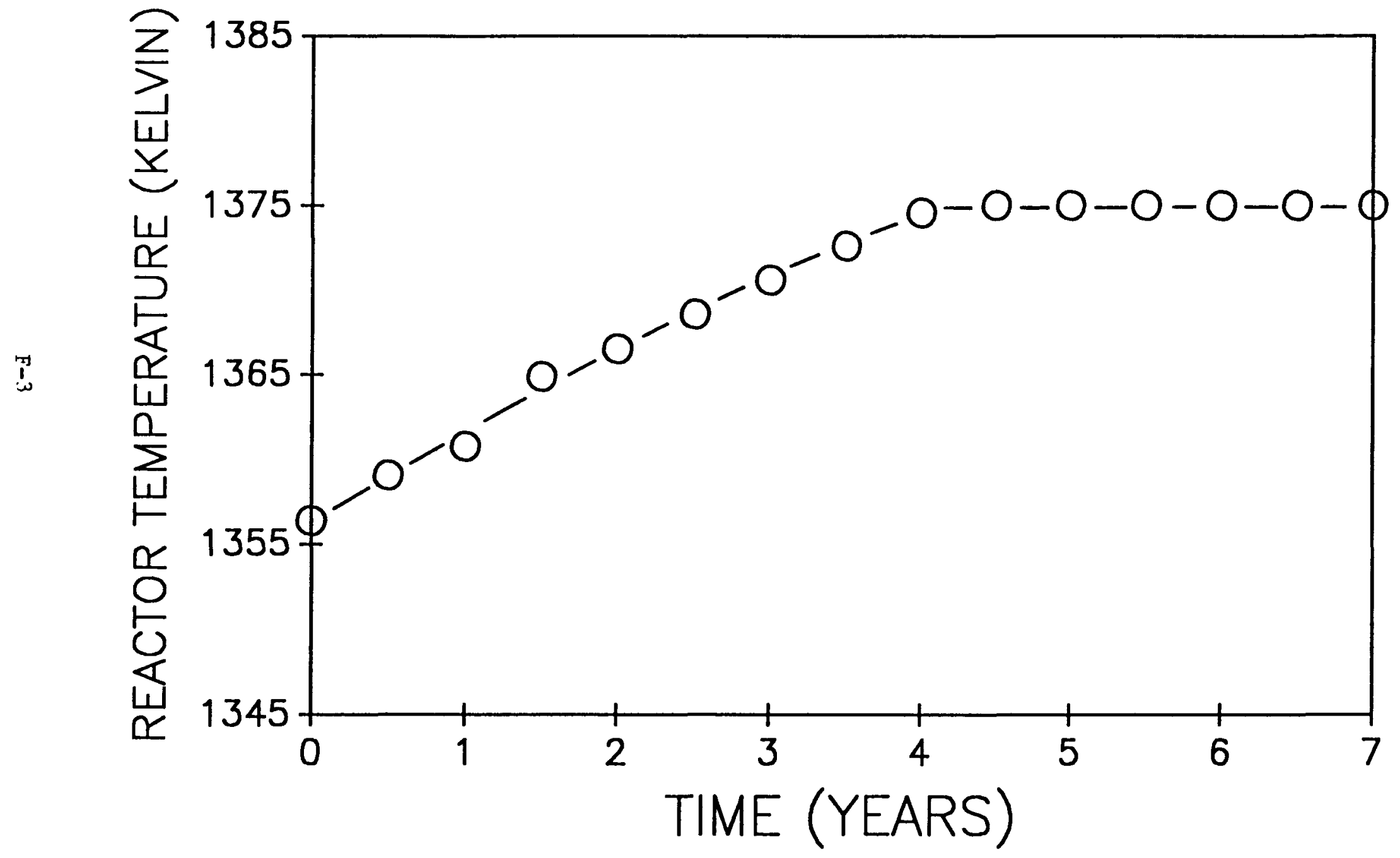

Figure 3. Baseline Reactor Temperature vs Time 


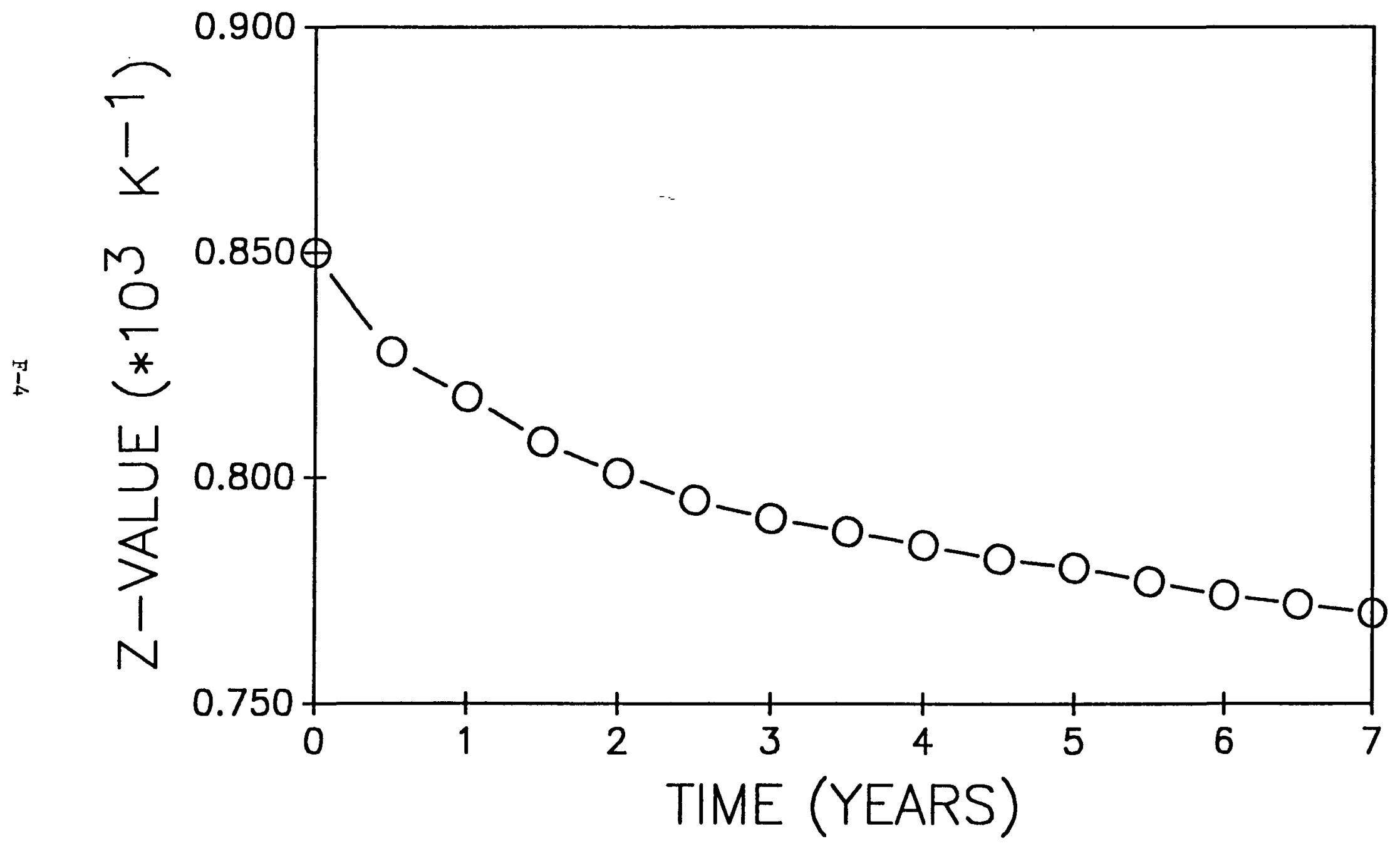

Figure 4. Z-Value vs Time 


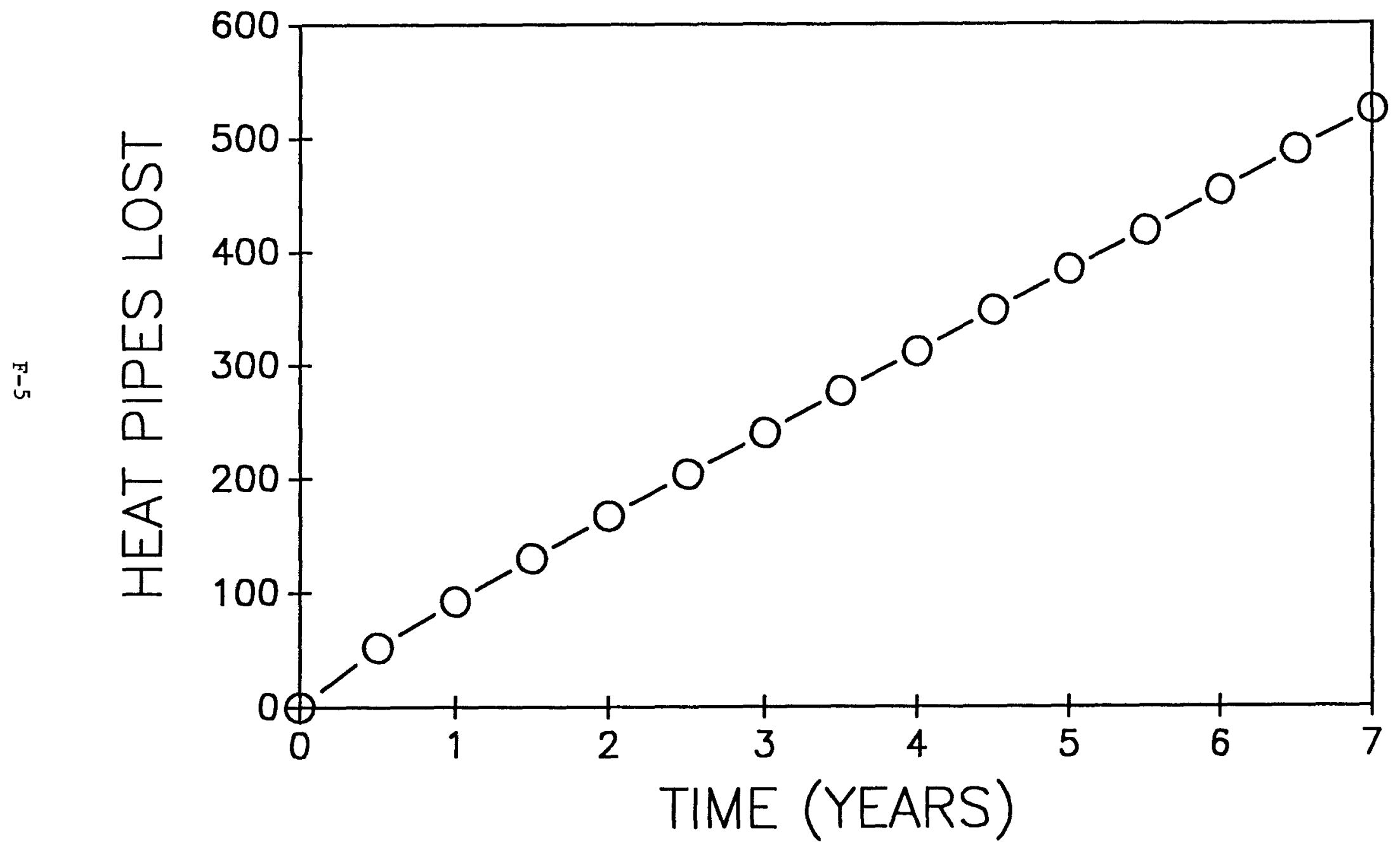

Figure 5. Heat Pipes Lost vs Time 


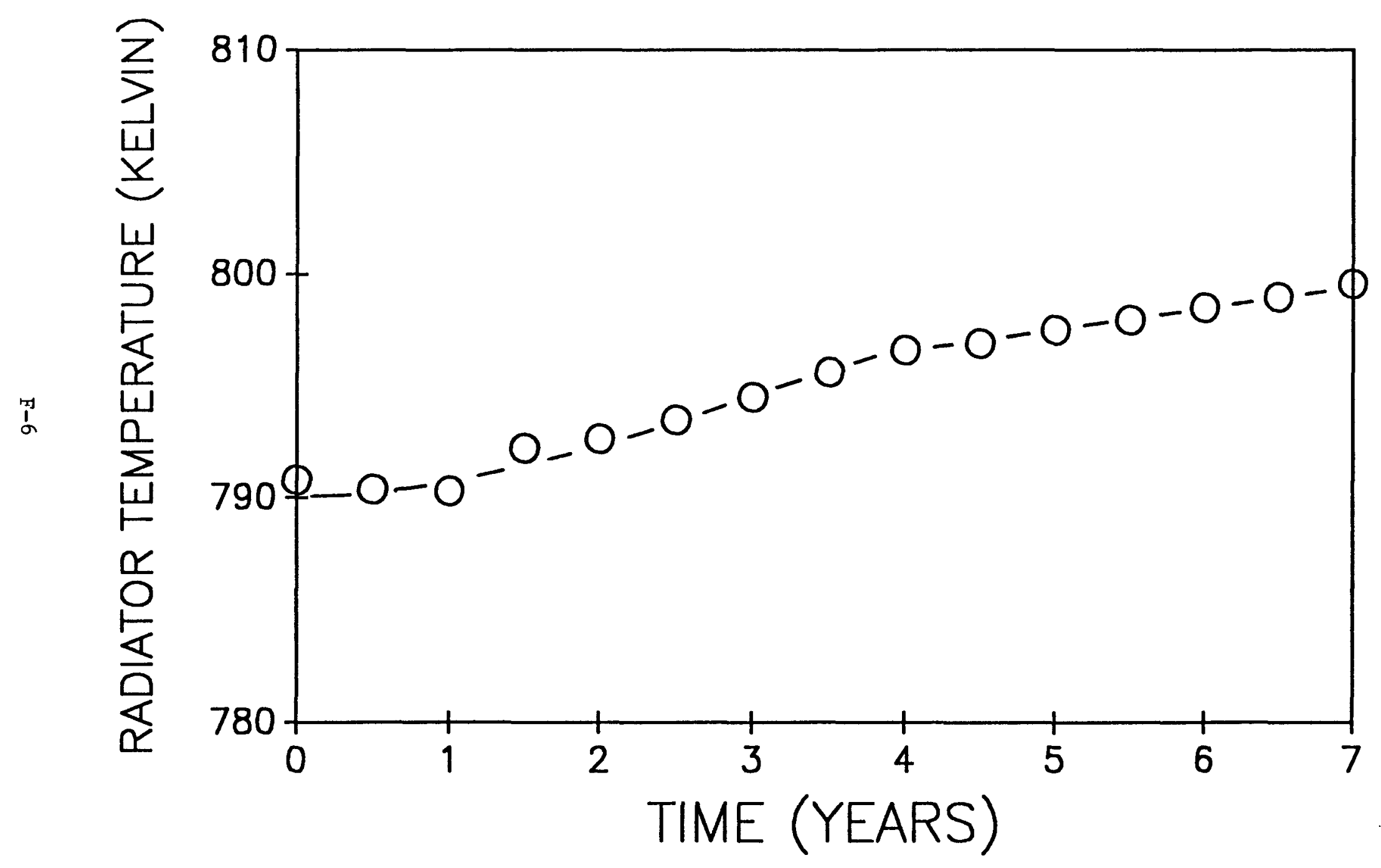

Figure 6. Baseline Radiator Temperature vs Time 


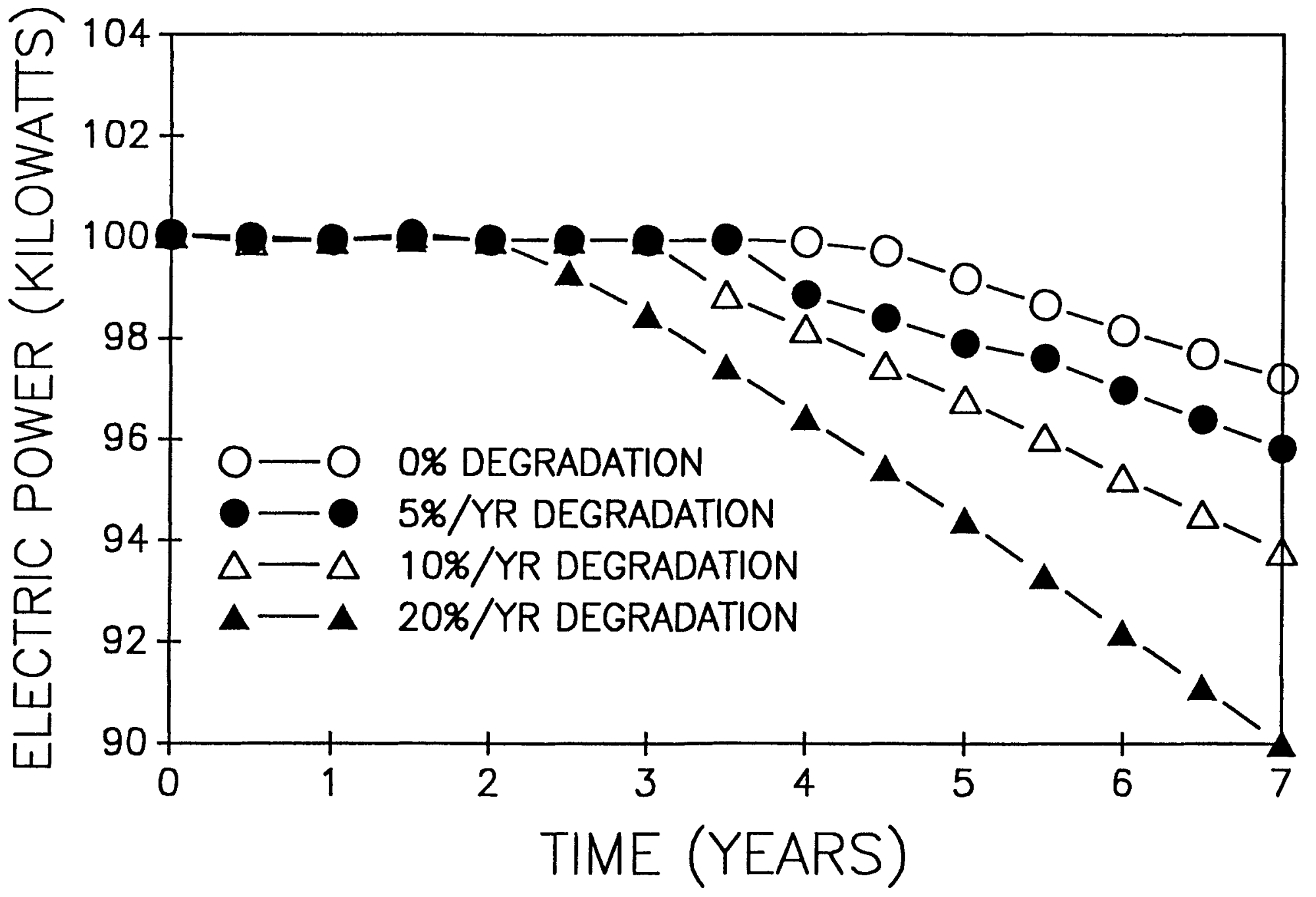

Figure 7. Effect of Primary Pressure Drop on Electric Power vs Time 


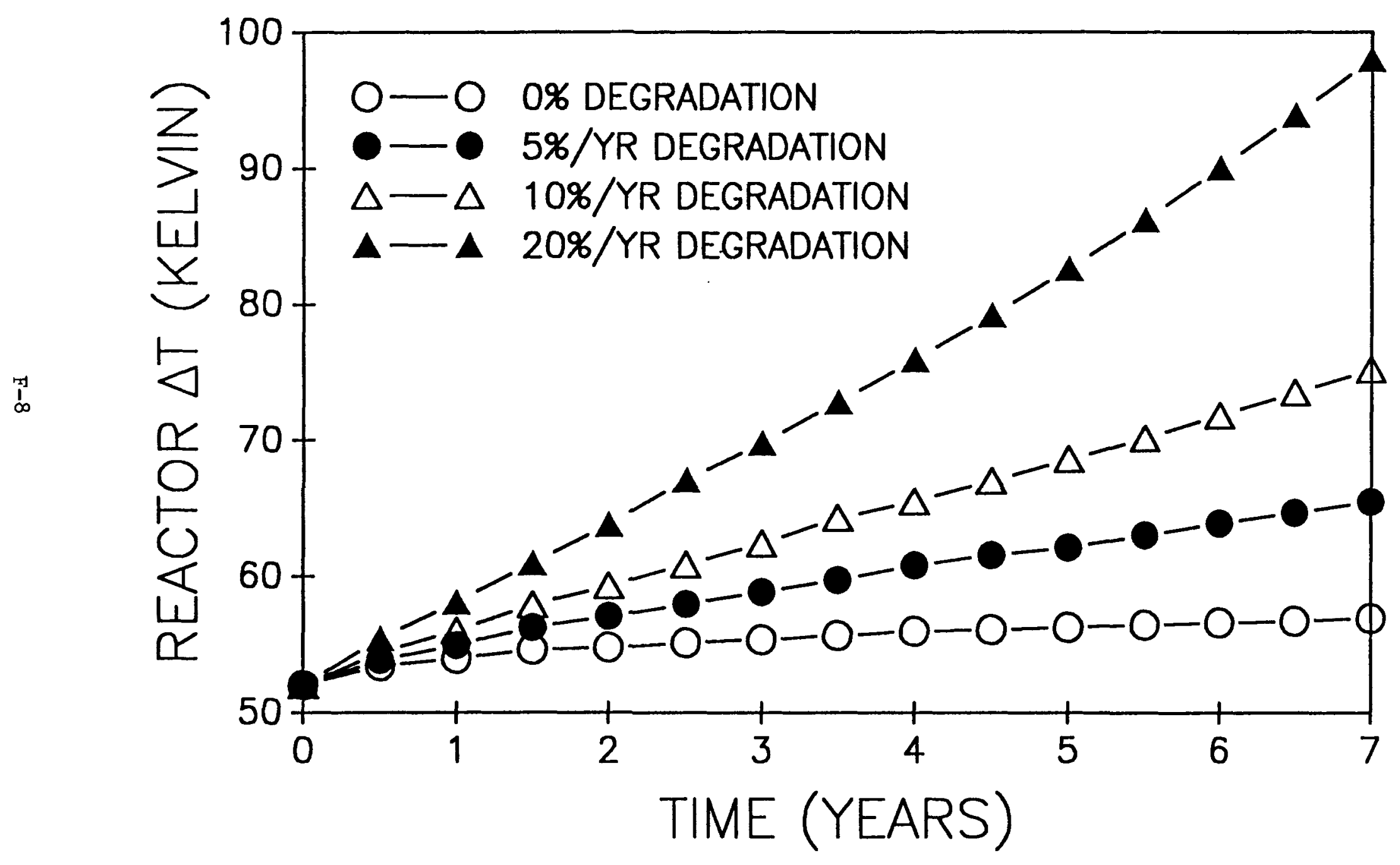

Figure 8. Effect of Primary Pressure Drop on Reactor $\Delta T$ vs Time 


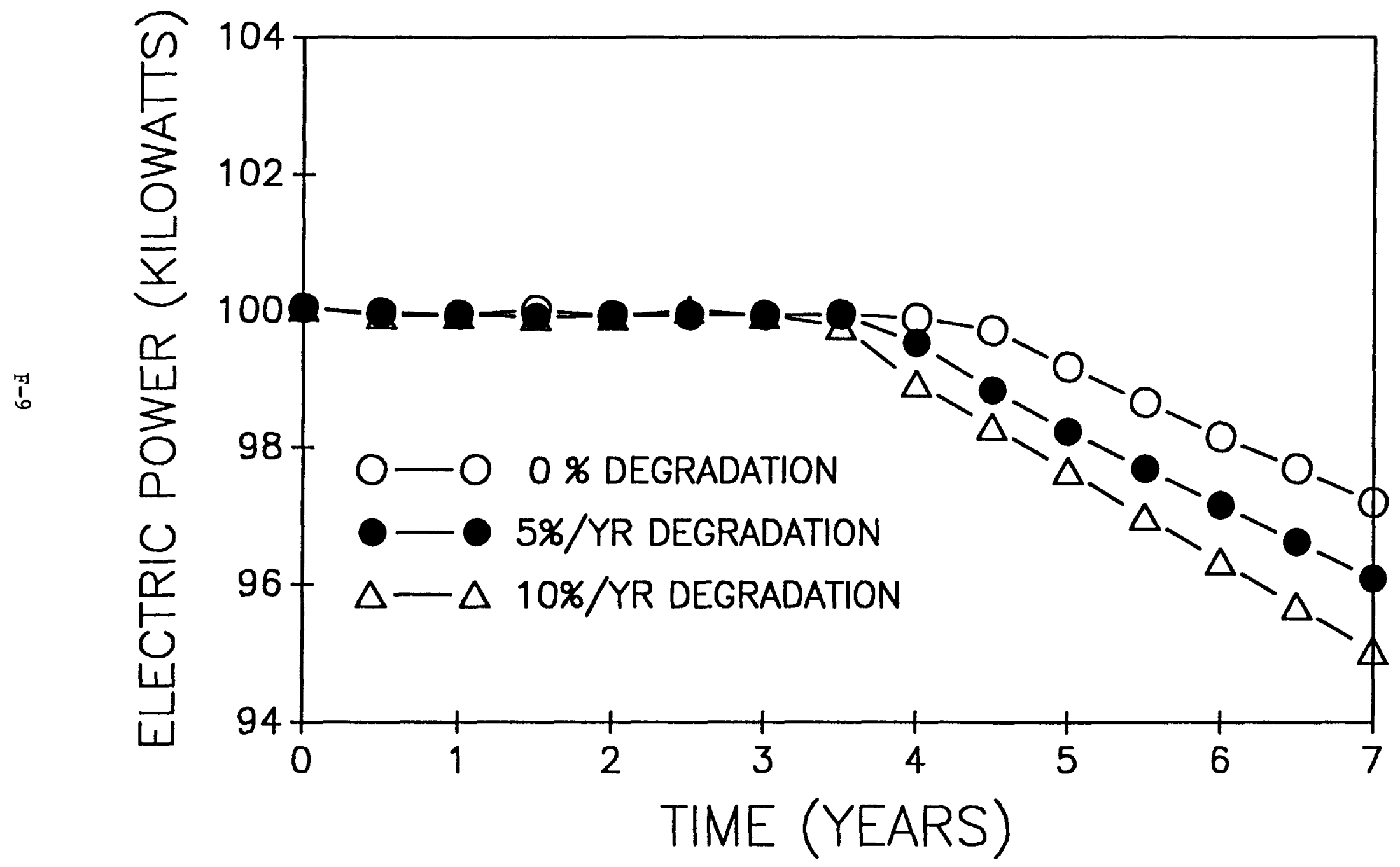

Figure 9. Effect of Secondary Pressure Drop on Electric Power vs Time 


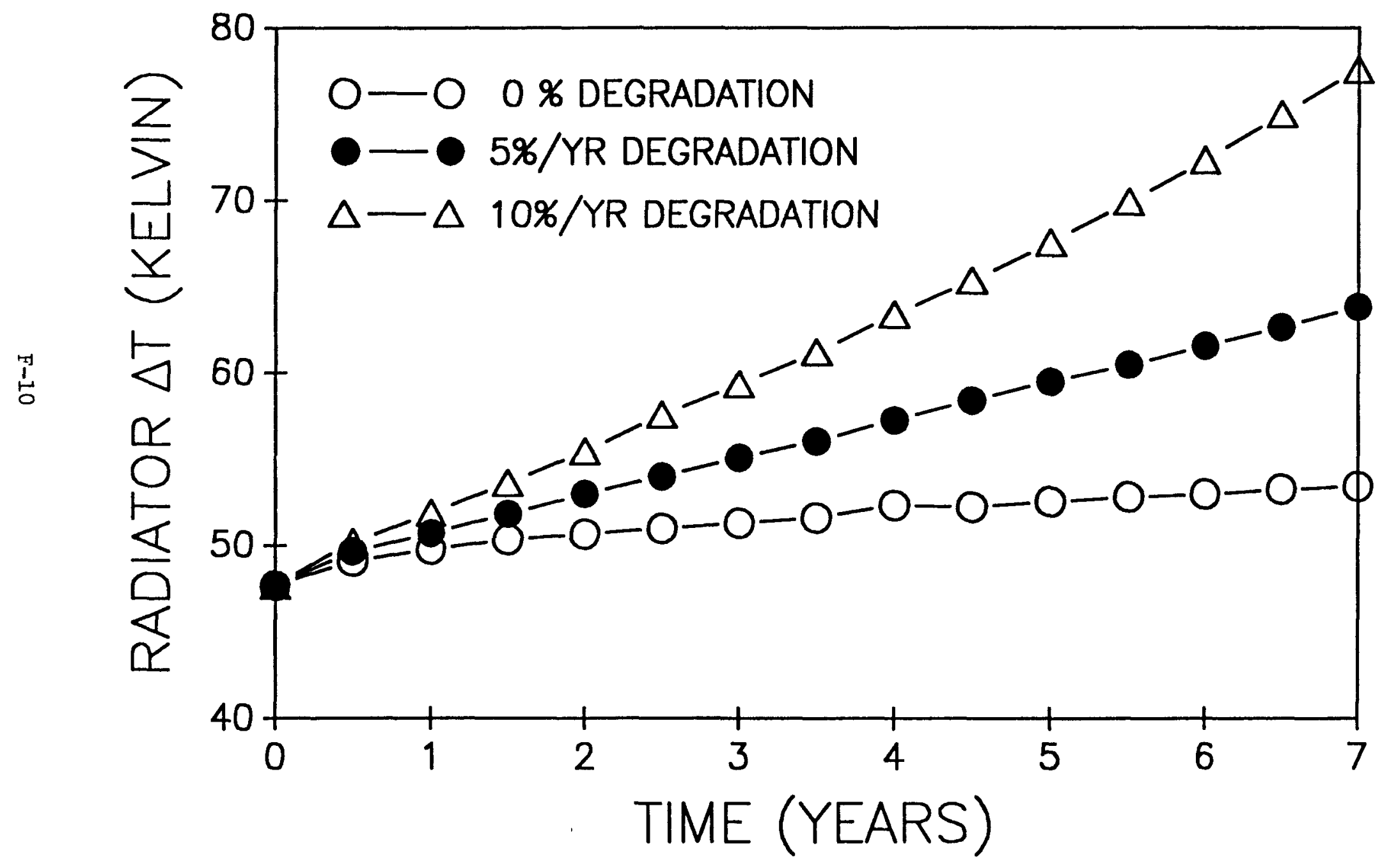

Figure 10. Effect of Secondary Pressure Drop on Radiator $\Delta T$ vs Time 


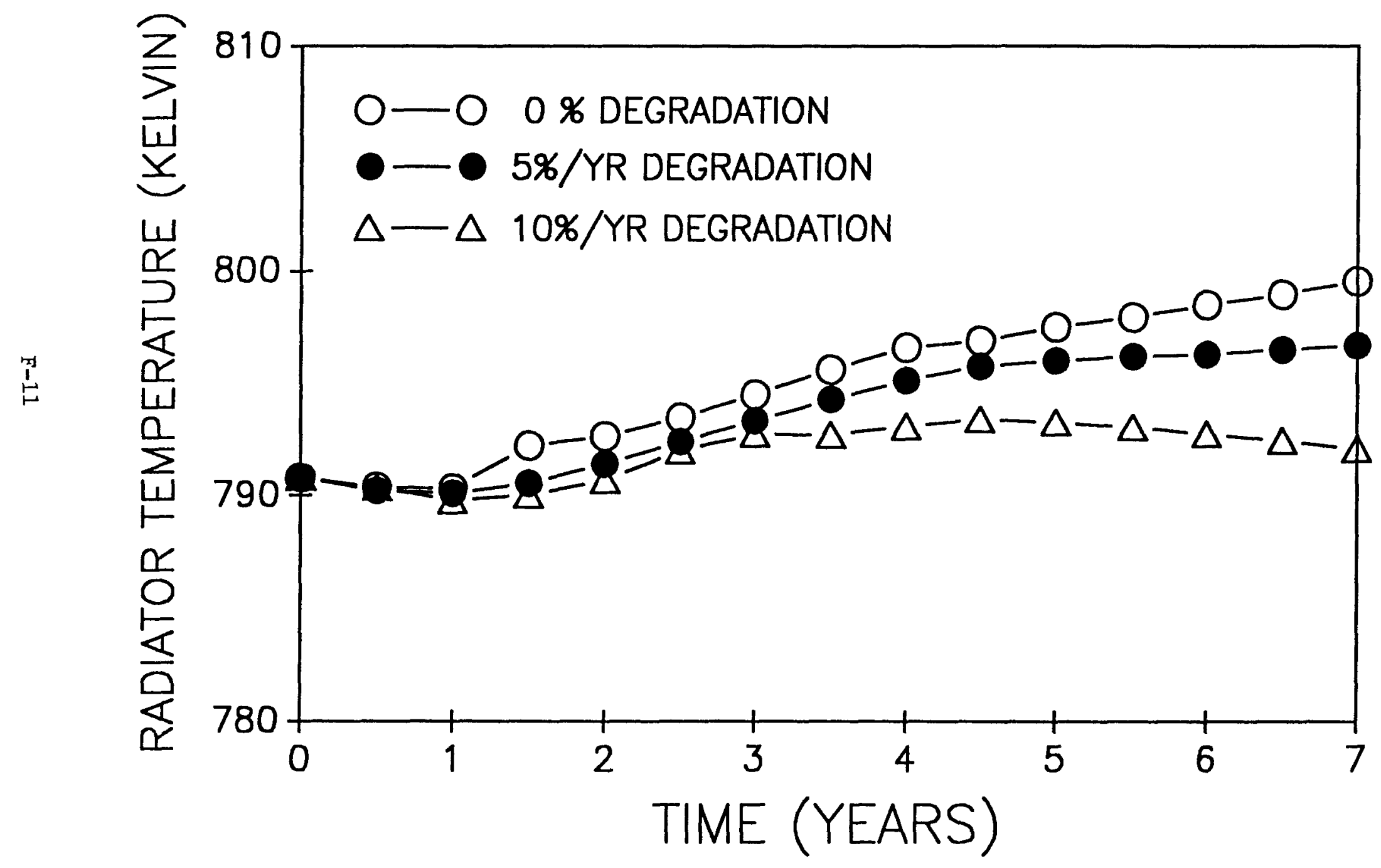

Figure 11. Effect of Secondary Pressure Drop on Radiator Temperature vs Time 


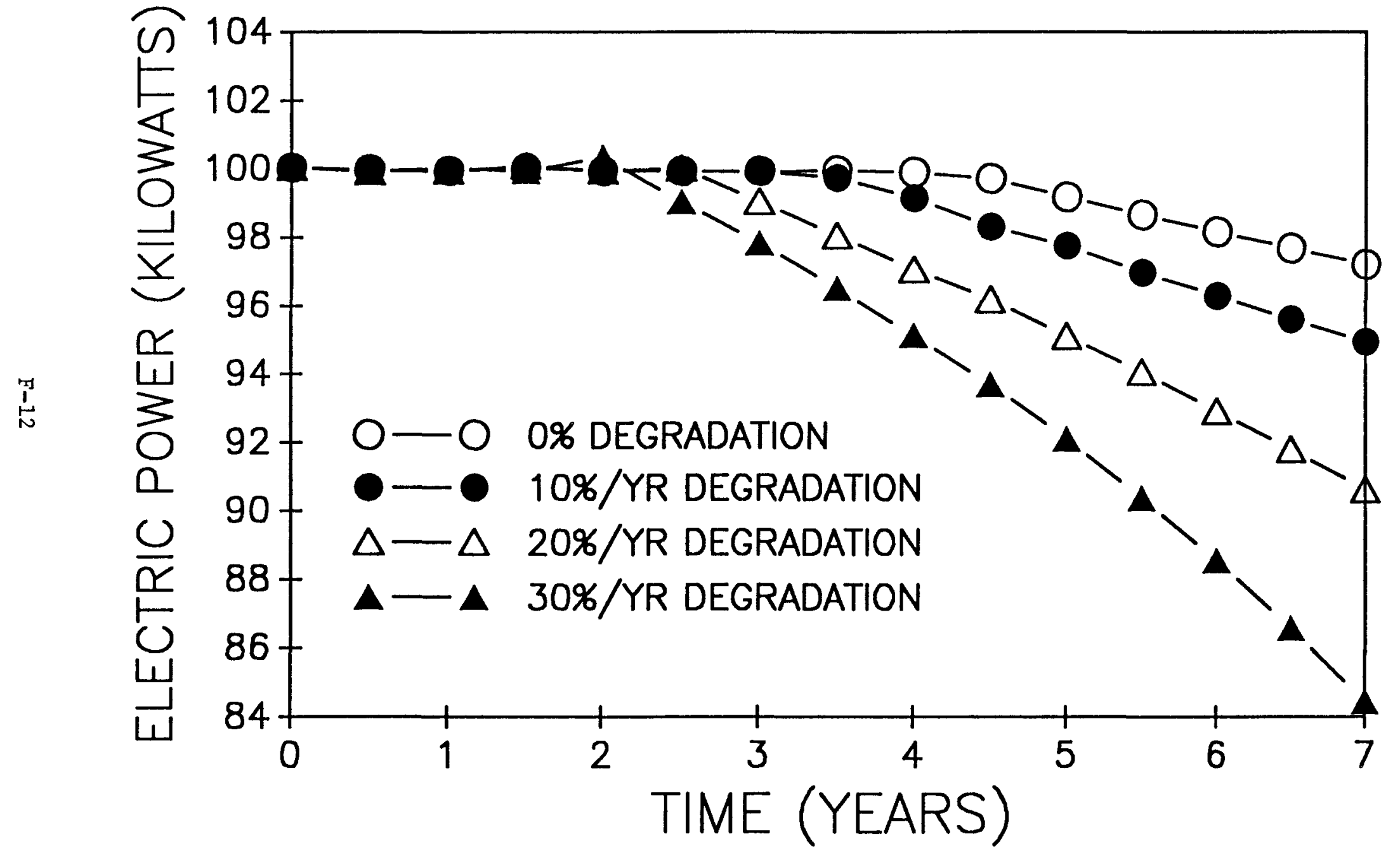




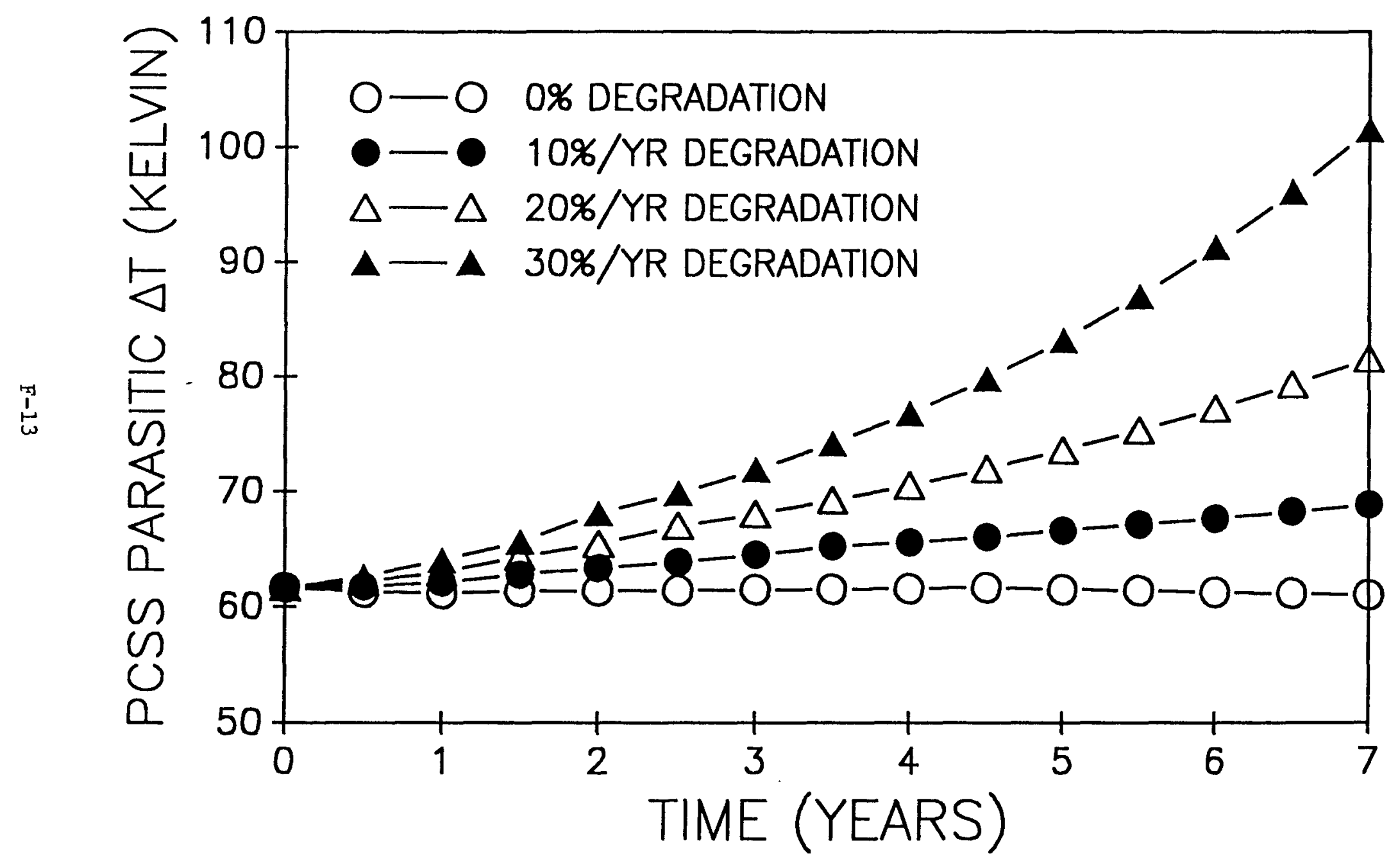

Figure 13. Effect of Thermal Contact Resistance on PCSS Parasitic $\triangle T$ vs Time 


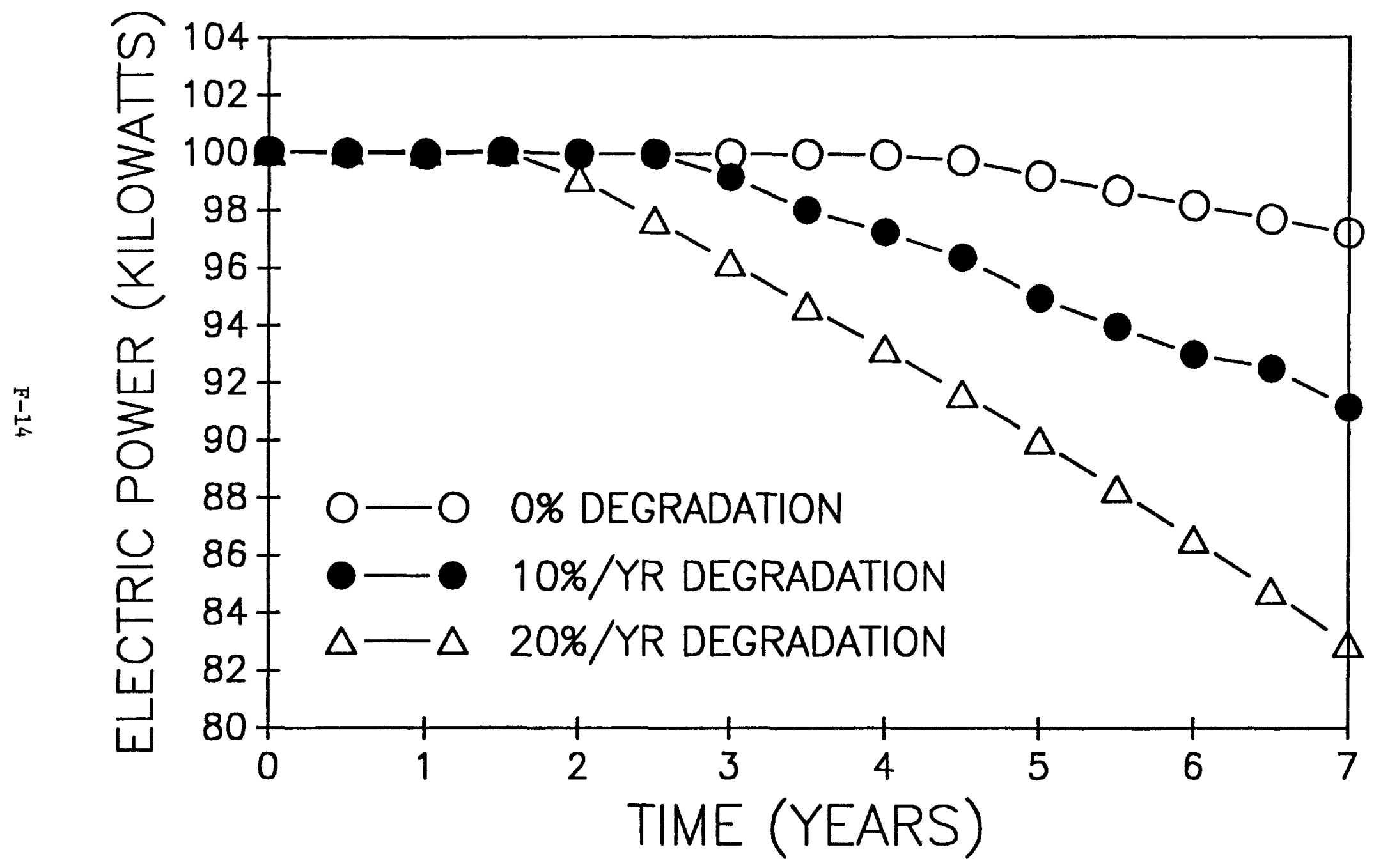

Figure 14. Effect of Electrical Contact Resistance on Electric Power vs Time 


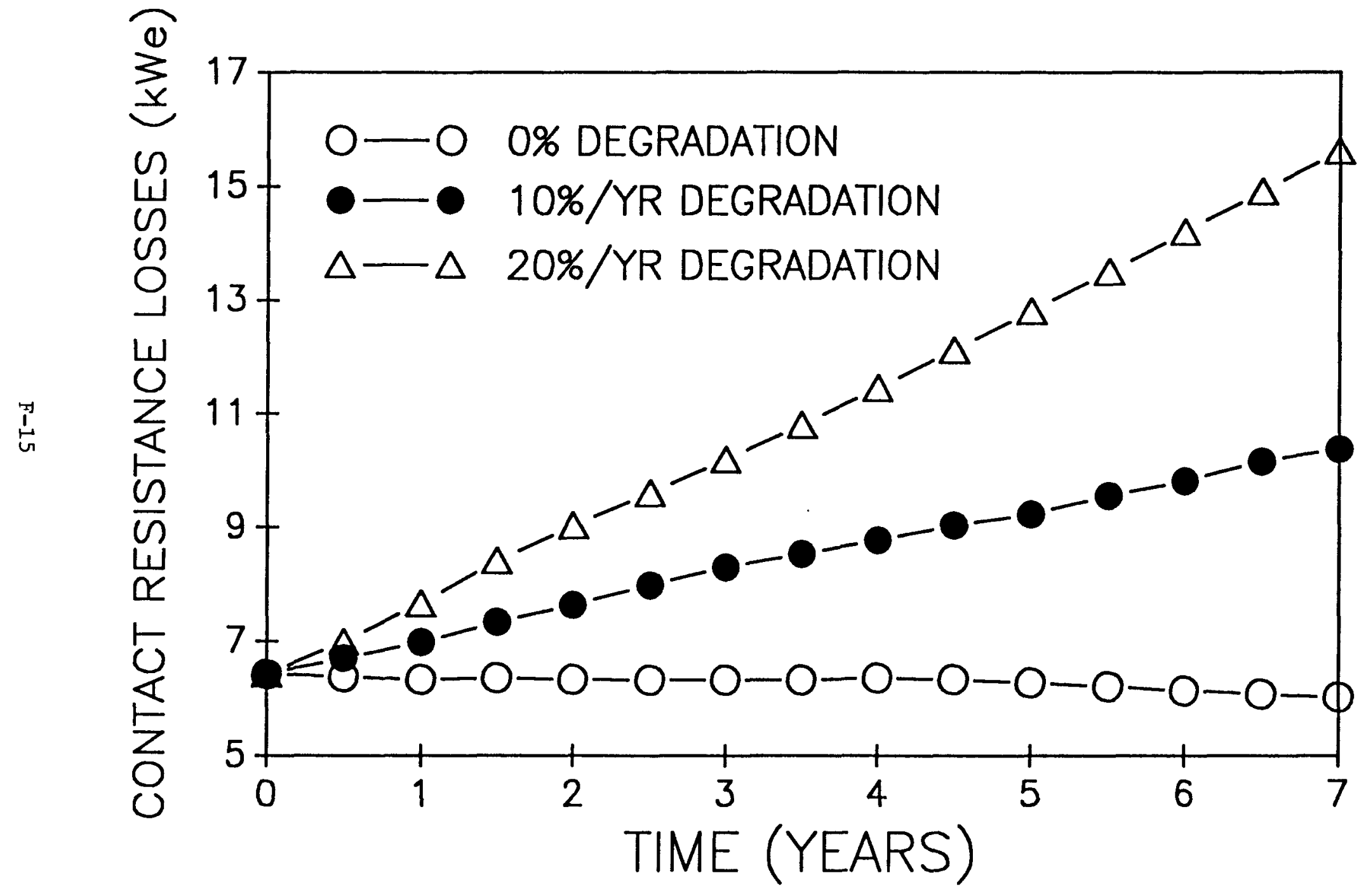

Figure 15. Effect of Electrical Contact Resistance on Contact Resistance Losses vs Time 


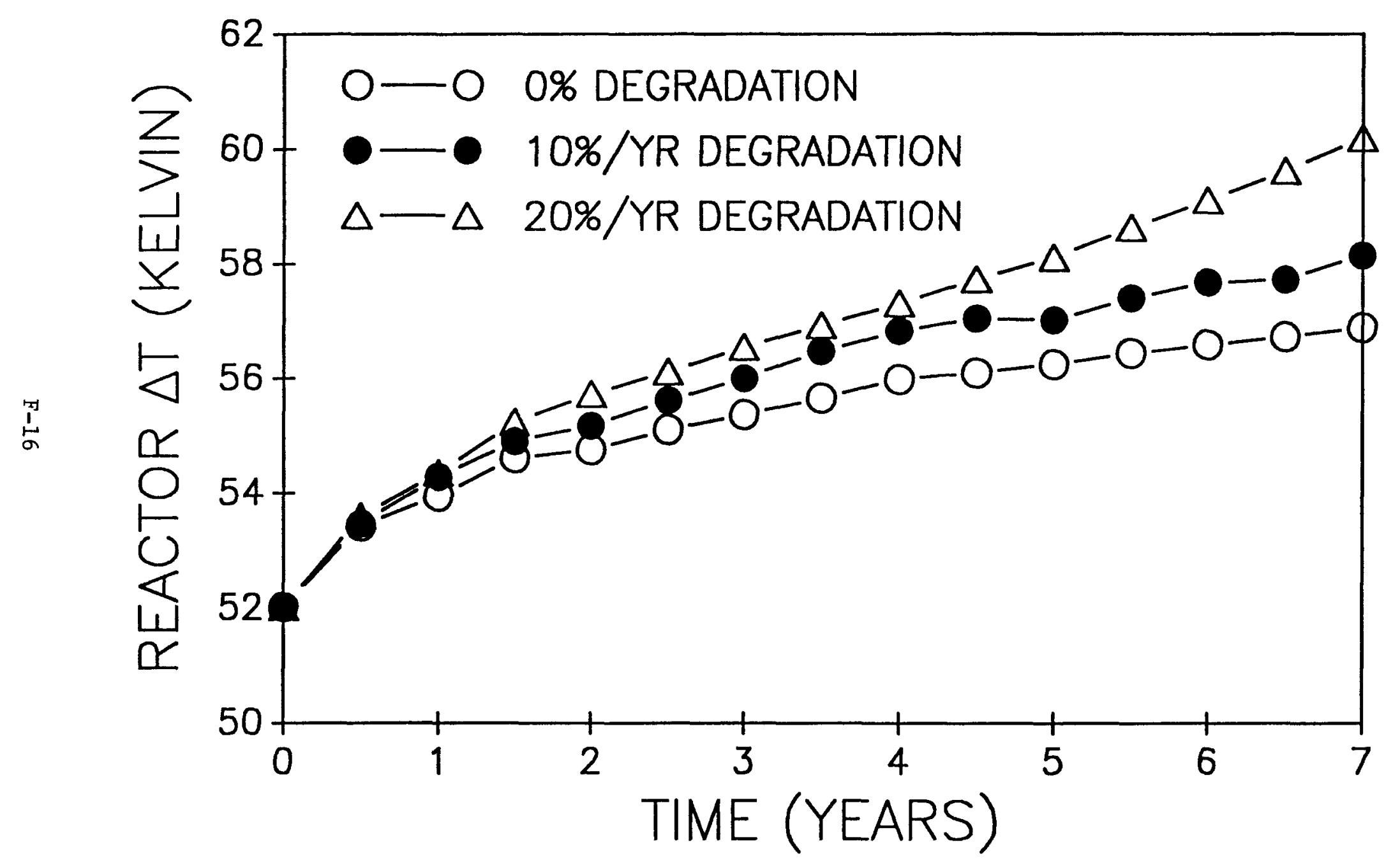

Figure 16. Effect of Electrical Contact Resistance on Reactor $\Delta T$ vs Time 


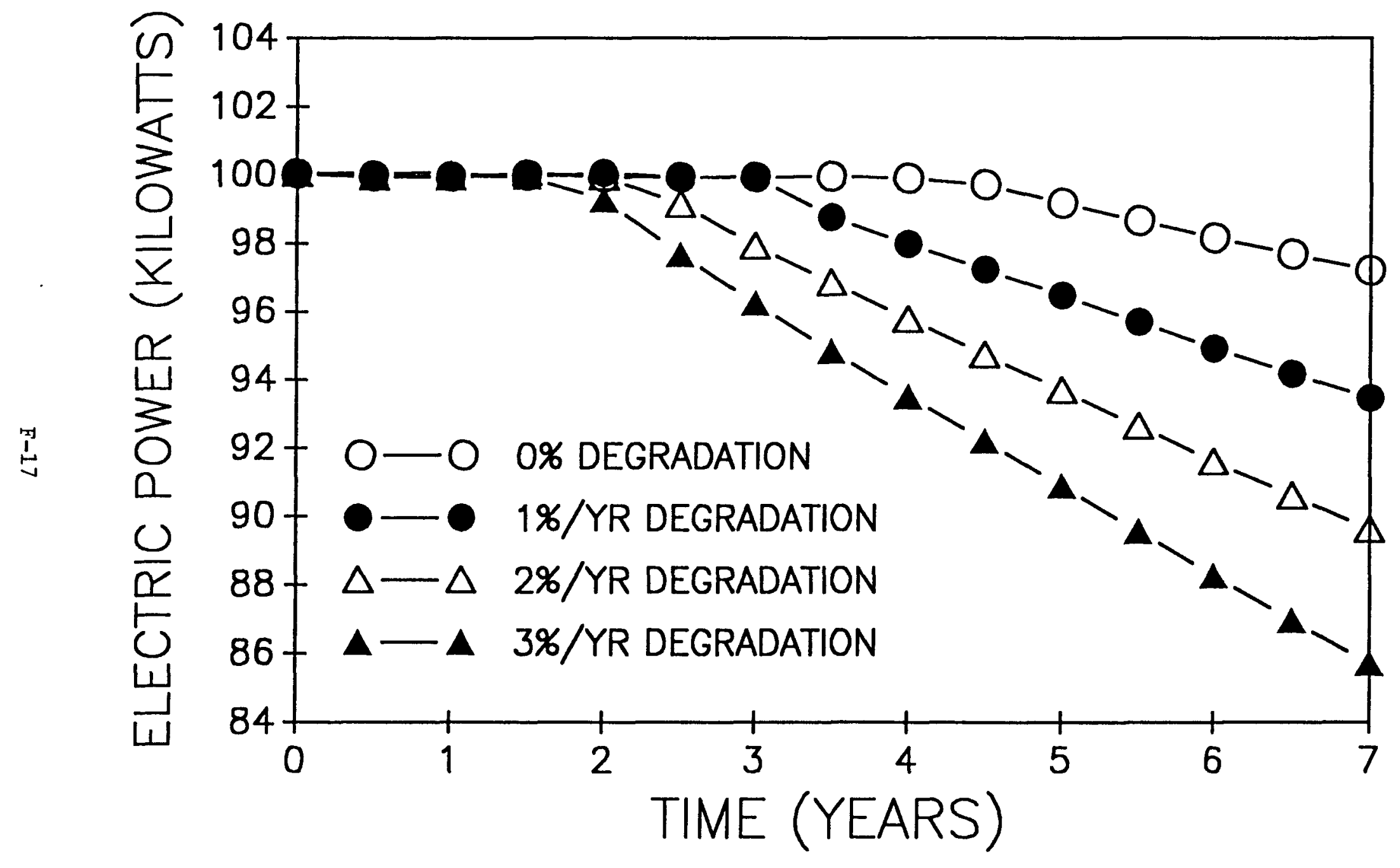

Figure 17. Effect of Radiator Emissivity on Electric Power vs Time 


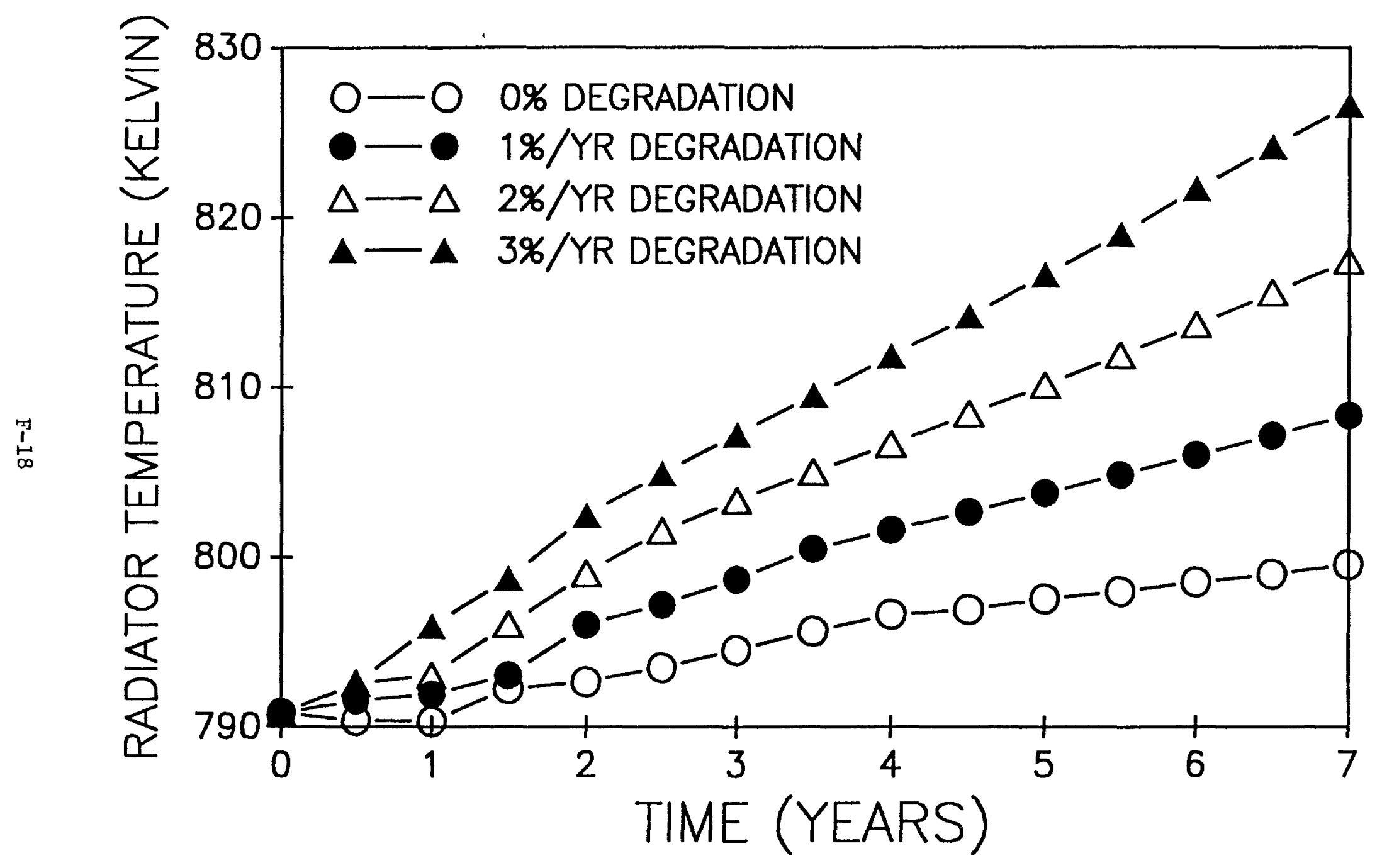

Figure 18. Effect of Radiator Emissivity on Radiator Temperature vs Time 
SECTION 11

REFERENCES

1. DEGRA 2 .. Implementation of a Computer Model for Predicting Long-Term Thermoelectric Generator Performance, JPL D-4734, October 12, 1987.

2. "Operational Life Model Computer Code Listing," IOM 342-91-RCE-007, November 2, 1990. 

K. Atkins
H. Awaya
P. Bankston
C. England
R. Ewell
T. Fujita
H. Gronroos

$303-300$

$303-308$

$303-300$

$122-108$

$303-308$

$157-102$

233-306
J. Klein

J. Mondt'

G. Stapfer

V. Truscello

$\mathrm{J}$. Vandersande

$R$. Wening
303-300

$122-108$

$122-108$

$122-108$

$277-212$

$111-141$

DL-1 